\title{
A synthesis of carbon dioxide emissions from fossil-fuel combustion
}

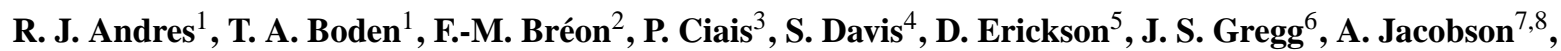 \\ G. Marland ${ }^{9}$, J. Miller ${ }^{7,8}$, T. Oda ${ }^{7,10}$, J. G. J. Olivier ${ }^{11}$, M. R. Raupach ${ }^{12}$, P. Rayner ${ }^{13}$, and K. Treanton ${ }^{14}$ \\ ${ }^{1}$ Environmental Sciences Division, Oak Ridge National Laboratory, Oak Ridge, TN 37831-6290 USA \\ ${ }^{2} \mathrm{CEA} / \mathrm{DSM} / \mathrm{LSCE}$, Gif sur Yvette, France \\ ${ }^{3}$ IPSL-LSCE, Gif sur Yvette, France \\ ${ }^{4}$ Carnegie Institution of Washington, Stanford University, Stanford, CA 94305 USA \\ ${ }^{5}$ Computational Earth Sciences Group, Computer Science and Mathematics Division, Oak Ridge National Laboratory, \\ Oak Ridge, TN 37831 USA \\ ${ }^{6}$ Risø DTU National Laboratory for Sustainable Energy, 4000 Roskilde, Denmark \\ ${ }^{7}$ NOAA Earth System Research Lab, Boulder, Colorado 80305 USA \\ ${ }^{8}$ Cooperative Institute for Research in Environmental Science, University of Colorado, Boulder, Colorado 80303 USA \\ ${ }^{9}$ Research Institute for Environment, Energy, and Economics, Appalachian State University, Boone, NC 28608 USA \\ ${ }^{10}$ Cooperative Institute for Research in the Atmosphere, Colorado State University, Fort Collins, Colorado 80523 USA \\ ${ }^{11}$ PBL Netherlands Environmental Assessment Agency, Bilthoven, The Netherlands \\ ${ }^{12}$ CSIRO Marine and Atmospheric Research, Australia \\ ${ }^{13}$ School of Earth Sciences, University of Melbourne, Australia \\ ${ }^{14}$ Energy Statistics Division, International Energy Agency, Paris, France
}

Correspondence to: R. J. Andres (andresrj@ornl.gov)

Received: 28 November 2011 - Published in Biogeosciences Discuss.: 31 January 2012

Revised: 17 April 2012 - Accepted: 24 April 2012 - Published: 25 May 2012

\begin{abstract}
This synthesis discusses the emissions of carbon dioxide from fossil-fuel combustion and cement production. While much is known about these emissions, there is still much that is unknown about the details surrounding these emissions. This synthesis explores our knowledge of these emissions in terms of why there is concern about them; how they are calculated; the major global efforts on inventorying them; their global, regional, and national totals at different spatial and temporal scales; how they are distributed on global grids (i.e., maps); how they are transported in models; and the uncertainties associated with these different aspects of the emissions. The magnitude of emissions from the combustion of fossil fuels has been almost continuously increasing with time since fossil fuels were first used by humans. Despite events in some nations specifically designed to reduce emissions, or which have had emissions reduction as a byproduct of other events, global total emissions continue their general increase with time. Global total fossilfuel carbon dioxide emissions are known to within $10 \%$ uncertainty (95\% confidence interval). Uncertainty on individ-
\end{abstract}

ual national total fossil-fuel carbon dioxide emissions range from a few percent to more than $50 \%$. This manuscript concludes that carbon dioxide emissions from fossil-fuel combustion continue to increase with time and that while much is known about the overall characteristics of these emissions, much is still to be learned about the detailed characteristics of these emissions.

\section{Introduction}

Emissions to the atmosphere of carbon dioxide $\left(\mathrm{CO}_{2}\right)$ from fossil-fuel combustion are of concern because of their growing magnitude, the resulting increase in atmospheric concentrations of $\mathrm{CO}_{2}$, the concomitant changes in climate, and the direct impact of increased atmospheric $\mathrm{CO}_{2}$ on ecosystems and energy demand. These ecosystem and climatic changes could adversely impact human society. This synthesis of information on fossil-fuel $\mathrm{CO}_{2}$ (FFCO2) emissions to the atmosphere is intended to summarize our current 
understanding about FFCO2 emissions to the atmosphere in support of the Regional Carbon Cycle Assessment and Processes project (RECCAP, http://www.globalcarbonproject. org/reccap). After introductory remarks, this synthesis includes a discussion of the different efforts to estimate global emissions (Sect. 2), an examination of the magnitude of global FFCO2 emissions (Sect. 3), the regional distribution (Sect. 4), national FFCO2 inventories (Sect. 5), the distribution of FFCO2 over space and time (Sects. 5.1, 5.2, and 6), issues related to FFCO2 transport in the atmosphere (Sect. 7), and uncertainties involved in estimates of $\mathrm{FFCO} 2$ emissions (Sect. 8).

FFCO2 inventories, created by an accounting of FFCO2 emissions per unit of time, have at their core a measure of the amount and type of fossil fuels consumed over a given time interval. Different inventories have different foci. Some are more focused on fuel production while others on fuel consumption. Some contain details about the sectors of the economy in which fuels are consumed while others focus on the type of fuel. Some attempt to survey all nations of the world while others focus on only certain nations. Some focus on emissions within national borders while others on emissions outside these borders (e.g., transoceanic shipping and aircraft or the emissions embodied in trade). Inventories can be focused on specific geographic areas or on particular industries, projects, products, activities, or time periods. Emission inventories serve a variety of objectives and can differ significantly with the myriad of scientific and sustainability questions posed. Thus, comparisons between inventories are not always straightforward.

The more complete inventories contain FFCO2 emissions from the three major fossil fuels: solid fuels (e.g., coal), liquid fuels (e.g., petroleum), and gaseous fuels (e.g., natural gas). Added to these inventories may be $\mathrm{CO}_{2}$ emissions from natural gas flaring and $\mathrm{CO}_{2}$ emissions from cement manufacture. Flaring of natural gas occurs as a byproduct of petroleum and natural gas extraction and processing. In oil fields that are not well connected to natural gas markets, for example, the co-produced natural gas is often burned at the well head because it is too expensive to capture and transport to market or re-inject into the ground. In areas deemed non-hazardous to humans, co-produced natural gas may also be vented instead of flared and these vented FFCO2 emissions are included as though they had been flared (an exception is EDGAR 4.2 which only tracks flaring for most countries (Olivier and Janssens-Maenhout, 2011)). No economic profit is made from this practice beyond avoiding costs associated with gas transport to market or re-injection. Cement manufacture is the process of converting calcium carbonate to lime with the $\mathrm{CO}_{2}$ byproduct being emitted to the atmosphere. Emissions from cement manufacture include only those from the carbonate to lime reaction (the emissions from burning fossil fuels to support this process are reported with the respective fossil fuels). Emissions from cement manufacture are often included because they are one of the largest,

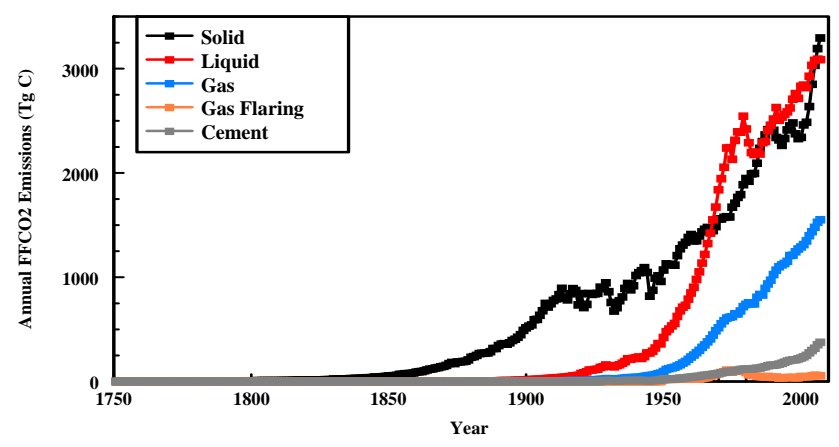

Fig. 1a. The contributions of five sources to FFCO2 emissions for the years 1751 to 2007 . This figure was created from the sum of national production values (see Sect. 1) for 15830 country-year pairs (e.g., the United Kingdom in 1751 is the first country year pair, the United Kingdom in 1752 is the second country-year pair, and Zimbabwe in 2007 is the 15830 th country-year pair). The distribution of country-year pairs is generally increasing with time with the year 1751 containing one country-year pair and 2007 containing 216 country-year pairs. Data richness (e.g., the number of country-year pairs) is increasing with time due to increased energy data availability and the formal recognition of more countries (as there has been a general trend for larger countries to divide into smaller countries (e.g., former USSR)). In 2007, solid fuels accounted for $39 \%$ of the 2007 total, liquid fuels $37 \%$, gas fuels $19 \%$, gas flaring $1 \%$, and cement $5 \%$ (percentages do not add to $100 \%$ due to rounding error). The unit of teragrams carbon ( $\mathrm{Tg} \mathrm{C}$ ) is equal to $10^{12}$ grams of carbon. To convert to $\mathrm{Tg} \mathrm{CO}_{2}$, multiply the total by the molar ratios of carbon dioxide to carbon (44.0/12.0) or 3.67. Data from Boden et al. (2010).

non-combustion, industrial sources of $\mathrm{CO}_{2}$ to the atmosphere and there are good statistics worldwide on cement production rates. Cement manufacture inclusion in some FFCO2 inventories reflects the desire to have a more complete accounting of anthropogenic emissions of $\mathrm{CO}_{2}$ to the atmosphere. Other industrial sources of $\mathrm{CO}_{2}$ to the atmosphere (e.g., as byproducts of acid production, steel production, etc.) are often not included in FFCO2 inventories because of incomplete production statistics; their relatively smaller size compared to cement production; and because their individual magnitude is generally smaller than the uncertainty associated with larger emissions from solid, liquid, and gaseous fuels. Figure 1a shows one estimate of the contributions of these five major sources of FFCO2 to the atmosphere globally.

FFCO2 data are compiled from fossil-fuel production data or fossil-fuel consumption data. Production data are usually used for global totals as the uncertainty associated with production data is less than the uncertainty associated with consumption data. Reasons for the differences in uncertainty associated with production and consumption data are given later in this manuscript, but they generally fall into the categories of fewer data points need to be collected for production values and these values are better known. 


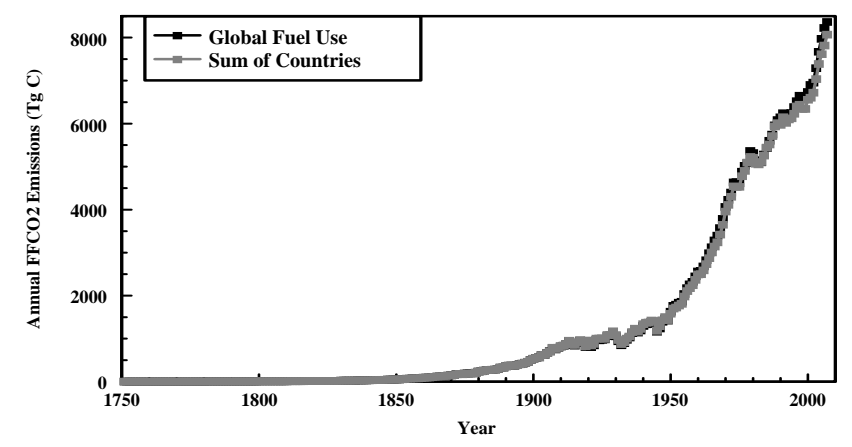

Fig. 1b. Comparison of FFCO2 emissions from global fuel use and the sum of countries for the years 1751 to 2007 . This figure was created from the sum of national production and consumption values for 15830 country-year pairs. Data from Boden et al. (2010).

Consumption data are usually used for totals smaller than global (e.g., region, country, province/state, corporation) because local specificity is needed to properly place fuel consumption in a particular area. This need for local specificity is removed when considering global totals. Fuel consumption is often not measured directly due to the lack of measurements (or statistics) at the appropriate spatial and temporal scales. Instead, fuel consumption is often inferred from estimates of apparent consumption where apparent consumption is defined as:

apparent consumption $=\Sigma$ (production + imports

- exports - bunkers - non - fuel uses - stock changes)

where the summation is done for solid fuels, liquid fuels, gas fuels, gas flaring, and cement (Marland and Rotty, 1984). Bunker fuels are fuels used in international transport (e.g., shipping and aviation) and by international convention are not attributed to any one country. "Non-fuel uses" applies to fuels that are not consumed directly for energy (e.g., petroleum liquids to make plastics and asphalt or natural gas to make fertilizers). Stock changes occur when fuels are accumulated or depleted in storage by producers, consumers, or shippers - usually in response to demand or price fluctuations. These additional terms are necessary to localize emissions statistics to a specific region as the location where a fuel is produced is often not the location where a fuel is consumed. Alternatively, FFCO2 emissions from specific enduses (e.g., transport, homes, businesses, etc.) can also be estimated from proxy data on fuel-consuming activities, such as vehicle kilometers driven or fuel receipts for heating.

The addition of these terms to calculate apparent consumption (hereafter referred to as consumption) creates more uncertainty in the consumption calculation as more detailed data from a larger number of fuel providers and consumers are needed. The collection of these more detailed data varies greatly, both in quality and quantity, between different countries and regions. The need for collection of these more detailed statistics is obviated at the global scale because im- ports should equal exports; bunker fuels are consumed; stock changes are often assumed equal to zero because of the relatively small amount of stock changes compared to overall fuel consumed annually (averaging less than $1 \%$, with a maximum of less than $3 \%$, of global totals for the years 1950-2007); and non-fuel uses are assumed equal to zero because over time these fuels are also eventually oxidized to $\mathrm{CO}_{2}$ (at different rates for different uses).

As can be seen in Fig. 1b, the total of FFCO2 emissions from global fuel use (i.e., calculated from production data) does not equal FFCO2 emissions reported as the sum of emissions from all countries (i.e., calculated from consumption data). These two curves differ by a maximum of $400 \mathrm{TgC}$ in the year 2006 (5\% in that year) and an average of $24 \mathrm{Tg} \mathrm{C}$ (less than $1 \%$ ) over the 257 -year record shown. The reasons for this discrepancy are fourfold: (1) bunker fuels are included in the global totals, but not in the national totals; (2) non-fuel uses are included in the global totals, but not in national totals that include data on non-fuel energy consumption; (3) changes in stocks are assumed to be zero each year in the global totals, but are included in national totals when reported for individual countries; and (4) the sum of exports does not equal the sum of imports due to statistical errors and incomplete reporting. Bunker fuels are the largest source of difference between the FFCO2 from global totals and the sum of FFCO2 from all countries.

Accurate FFCO2 emissions inventories contribute knowledge to better understand the physical and economic environment in which society exists and allow monitoring and verification efforts to reduce emissions. For example, via transport modeling (see Sect. 7), flux units of mass per time of FFCO2 inventories can be converted to the concentration units of $\mathrm{CO}_{2}$ in the atmosphere (e.g., parts per million, ppm, Forster et al., 2007). On the physical environment side, FFCO2 inventories also help to understand: (1) the systematic trend of $\mathrm{CO}_{2}$ concentration between northern and southern hemispheres (Denman et al., 2007); (2) the trend in stable carbon isotopes of atmospheric $\mathrm{CO}_{2}\left(\delta^{13} \mathrm{C}\right.$, Ciais et al., 1995); (3) the trend in radiogenic carbon isotopes of atmospheric $\mathrm{CO}_{2}\left(\Delta^{14} \mathrm{C}\right.$, Levin et al., 2010); and (4) the trend in oxygen concentrations in the atmosphere (Keeling et al., 1993). FFCO2 emission inventories are consistent with these four atmospheric trends and are integral to their current explanation. On the economic side, FFCO2 inventories (particularly those with economic sectoral detail) also help to understand the relationships between fossil-fuel use and economic vitality (e.g., Olivier et al., 2011; IEA, 2010; Raupach et al., 2007; Bernstein and Roy, 2007; Levine and Ürge-Vorsatz, 2007; Ribeiro and Kobayashi, 2007; Kashiwagi, 1996; Michaelis, 1996). As it becomes increasingly apparent that the atmospheric concentration of $\mathrm{CO}_{2}$ needs to be limited, it is increasingly important to understand the sources of $\mathrm{CO}_{2}$, the activities and actors that are responsible for emissions, the success of mitigation efforts, and the extent to which the 
many countries/parties are meeting their commitments to limit their emissions.

As this synthesis details, there are numerous methods for estimating $\mathrm{CO}_{2}$ emissions over space and time. In general, these emissions are attributed to the activities, regions, countries, and time intervals over which they are produced (i.e., where and when fossil fuels are burned or otherwise used). However, fuels burned in one country may have been extracted in another country and the resulting goods consumed in yet another country. In such cases, attribution of all emissions to the countries where the fuels are burned neglects the role of the countries extracting and exporting fossil fuels as well as the countries that either consume goods produced elsewhere or produce goods to be consumed elsewhere. Recent publications have quantified the lateral fluxes of fossil fuels transported internationally before being burned (Davis et al., 2011), as well as the FFCO2 emissions embodied in goods traded internationally (Peters et al., 2011; Davis and Caldeira, 2010). A separate RECCAP synthesis (Peters and Davis, 2012) assesses this literature.

\section{Different global data sets available}

There are currently four organizations that produce systematic, global, annual estimates of FFCO2 emissions: The Carbon Dioxide Information Analysis Center (CDIAC, http:// cdiac.esd.ornl.gov), the International Energy Agency (IEA, http://www.iea.org), the Energy Information Administration of the United States (US) Department of Energy (EIA, http: //www.eia.doe.gov), and a joint effort of the Joint Research Centre of the European Commission and PBL Netherlands Environmental Assessment Agency (Emission Database for Global Atmospheric Research (EDGAR), http://edgar.jrc.ec. europa.eu). An additional data set, compiled by the United Nations Framework Convention on Climate Change (UNFCCC), summarizes emissions data reported by signatory countries and covers many countries, in particular most of the industrialized countries with large emissions. In general all of the emission estimates within these inventories agree with each other, for both global and national emissions, within about $\pm 5 \%$ for developed countries and within about $\pm 10 \%$ for developing countries (which generally have less resources and commitment to data collection and reporting). These compilations all rely on estimates of how much fuel is consumed, estimates of average carbon content of the fuels consumed, and estimates of the fraction of fuel consumption that results in actual oxidation (i.e., combustion) of each fuel commodity. The fuel oxidation term is important as it assumes immediate oxidation to FFCO2. This ignores kinetic and other chemical effects and becomes important when measured atmospheric carbon concentration data is compared to model output (see Enting et al., 2012 and references therein; Boucher et al., 2009). The four global data sets listed above experience a lag time between the current calendar year and their latest year of reported data due to the time needed to collect, analyze, calculate, and report the various data involved. In an effort to report more recent calendar year data, data from the BP Statistical Review of World Energy have been used to estimate global FFCO2 emissions (e.g., LeQuere et al., 2009).

The four global emissions data sets start with energy data from different sources, but ultimately all of the data come from national or corporate surveys and reporting. Energy statistics compiled by the IEA and the United Nations Statistics Office (UNSO), for example, are now collected from many countries with a common survey form. Nonetheless, the various international statistics are subject to differences in emphases, categories, units, unit conversions and reporting, data processing, and quality assurance within the host organizations. The international statistics compilers are also left to fill in the blanks when countries provide incomplete data or do not respond at all (a common occurrence in some African countries, for example). The completeness and quality of data are extremely variable around the world and the uncertainty of the data is also variable. Nonetheless, the production, consumption, and trade of fossil fuels have great economic importance and at least some records are available back to the beginning of the industrial revolution. Using data from a variety of sources, CDIAC has assembled estimates of $\mathrm{CO}_{2}$ emissions, by country, that are reasonably complete back to 1751 (Andres et al., 1999). Notably, more than half of cumulative fossil-fuel consumption globally has been since 1980 so that overall accuracy is dominated by data from the most recent years. Similarly, emissions are, and have always been, dominated by a small number of countries (currently 20 countries are responsible for about $80 \%$ of global emissions) so that uncertainty on the global total is dominated by data from a small number of countries.

In general, the large global compilations of emissions estimates rely on international compilations of energy data and global average emissions factors, whereas the estimates of emissions from individual countries are able to use local understanding of data idiosyncrasies and locally focused emissions factors. The result is that the global data sets produce estimates that should be uniform and comparable across countries and across time, but the individual country estimates may include details based on insights that are uniquely representative of the countries that produced them.

There have been several analyses that attempted systematic comparison across these multiple data sets. For example, the IEA now routinely compares its estimates with those reported by the individual countries to the UNFCCC. They report that "for most Annex II countries, the two calculations were within $5 \%$. For some EIT (economies in transition) and non-Annex I countries, differences... were larger. In some of the countries the underlying energy data were different; suggesting that more work is needed on the collecting and reporting of energy statistics for these countries" (OECD/IEA, 2010). Marland et al. (1999) pursued a 
systematic comparison of the CDIAC and EDGAR data sets and Marland et al. (2007) reported a systematic comparison of estimates from CDIAC, EIA, and UNFCCC for the three countries of North America. Macknick (2009) has recently attempted a systematic comparison of four emissions data sets, and Ciais et al. (2010) have done a similar comparison for the countries of the European Union. A conclusion from these comparisons is that despite apparent similarity, there are differences in assumptions and boundary conditions that make it difficult to do quick quantitative comparisons. These differences result from, among other things, the inclusion of $\mathrm{CO}_{2}$ from calcining limestone to make cement, the inclusion of emissions from fuels used in international transport, the treatment of fossil fuels that are used in non-fuel applications, the treatment of natural gas flaring, and the treatment of fuels used for military purposes. Figure 2 and Table 1 summarize the published comparisons. This figure and table emphasize some of the subtle differences in the different data sets. These differences are, of course, specifically characterized in the documentation of each of the data sets, but their significance may not be readily apparent to data users.

Emissions reported annually by CDIAC are primarily derived from energy statistics published by the UNSO, which in turn reflect responses to United Nations (UN) and IEA questionnaires; official, national statistical publications; and the best estimates of the UNSO (Marland and Rotty, 1984; Andres et al., 1999; Boden et al., 2010). The total FFCO2 emissions reported in this manuscript are from fuel production data (see Sect. 1) and include, for each of 224 nations or territories, emissions from bunker fuels (which for bookkeeping purposes are allocated to the country where the fuels are loaded), natural gas flaring, calcining of limestone during cement production, and non-fuel uses.

Emissions reported annually by the IEA are primarily derived from sectoral energy statistics gathered by their own questionnaire, data sharing with the UNSO, official statistical publications, and the best estimates of the IEA staff. The IEA estimates global emissions using both a Tier 1 Sectoral Approach and the Reference Approach following the methodology of the IPCC Guidelines for National Greenhouse Gas Inventories (IPCC, 1996). The IEA has chosen to use the Revised 1996 IPCC Guidelines based on advice from the UNFCCC since the Kyoto Protocol is based on this version of the Guidelines. This comparison is based on the Reference Approach calculations and is a modified version of the apparent consumption discussed in section 1 since the non-fuel uses are not subtracted from the apparent consumption, but an adjustment is made further along in the calculation to exclude the non-fuel uses. The total FFCO2 emissions reported in this manuscript include, for each of 140 nations or regions, emissions from bunker fuels (bunker fuels are not included in national totals in IEA publications, but are shown separately by the IEA and included in their global totals). The IEA estimates do not include gas flaring, calcin-

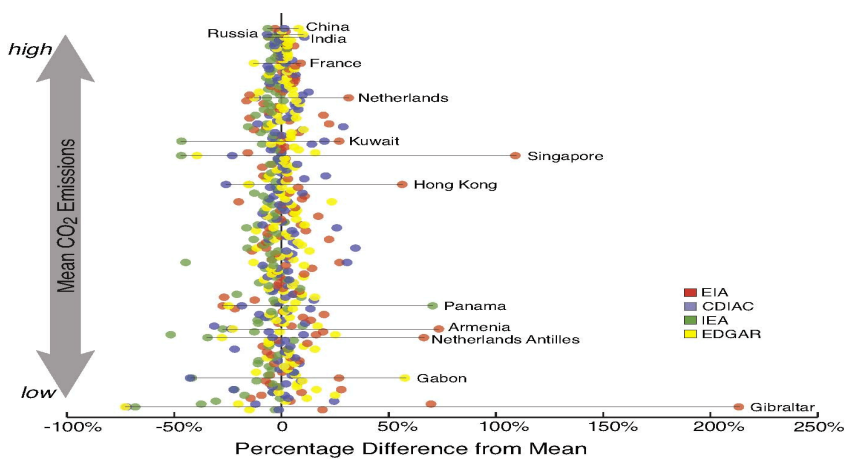

Fig. 2. Differences in total emissions reported by CDIAC, IEA, EIA, and EDGAR for 133 nations in 2007. The nations are spread along the $y$-axis according to their rank-order of mean FFCO2 emissions as reported in the respective data sets. Points near zero on the $\mathrm{x}$-axis reflect small differences among the total emissions reported. Outliers reflect larger differences related to the disparate methodologies underlying reported emissions, for instance whether or not emissions from international bunker fuels and calcining of limestone are included.

ing of limestone during cement production, nor non-fuel uses (OECD/IEA, 2010).

Emissions reported annually by the EIA are primarily derived from EIA-collected energy statistics from national statistical reports. The EIA calculation methodology is similar to the CDIAC apparent consumption methodology, but the EIA uses internally generated carbon content and fraction oxidized coefficients. The total FFCO2 emissions reported in this manuscript include, for each of 224 nations or territories, emissions from bunker fuels (which are allocated to the country where the fuels are loaded), natural gas flaring, and non-fuel uses. The EIA estimates do not include calcining of limestone during cement production (EIA, 2011a).

Emissions reported annually by the EDGAR effort are primarily derived from sectoral IEA energy statistics and default emission factors from the IPCC Guidelines (IPCC, 2006), and are presented in sectoral categories recommended by the IPCC (IPCC, 2006). The total FFCO2 emissions reported in this manuscript include, for each of 214 nations or territories, emissions from bunker fuels, natural gas flaring, calcining of limestone during cement production, and non-fuel uses using the 2006 IPCC tier I methods (EC-JRC/PBL, 2011). The most recent full version of EDGAR (4.2) also reports other greenhouse gases.

The Parties to the UNFCCC are required to report periodically on their GHG emissions. The 42 Parties that are listed in Annex I (industrialized nations and the European Union) are supposed to submit detailed emission reports annually; the 152 non-Annex I (developing nations) Parties less frequently submit less detailed reports as part of their National Communications. Submitted reports are calculated by the individual Parties according to IPCC Guidelines (IPCC, 1996), and therefore include emissions from flaring of natural gas, 
Table 1. Comparison of five global FFCO2 emissions inventories.

\begin{tabular}{|c|c|c|c|c|c|}
\hline & CDIAC & IEA & EIA & EDGAR & UNFCCC \\
\hline First year in data set & 1751 & 1971 & 1980 & 1970 & \\
\hline Update frequency & Annual & Annual & Annual & Annual/Periodic & Annual/Periodic ${ }^{\mathrm{a}}$ \\
\hline Source of energy data & UN & IEA & EIA & IEA & National sources \\
\hline Countries included & 224 & $137^{\mathrm{b}}$ & 224 & 214 & 191 \\
\hline Bunker fuels & $\mathrm{Yes}^{\mathrm{c}}$ & Yes $^{c}$ & Yes & $\mathrm{Yes}^{\mathrm{c}}$ & Reported separately \\
\hline Gas flaring & Yes & No & Yes & Yes & Yes \\
\hline Calcining limestone & Yes & No & No & Yes & Yes \\
\hline Non-fuel uses & Yes $^{c}$ & No & Yes & Yes & Yes \\
\hline $\begin{array}{l}\text { Global total emissions } \\
\text { for } 2005(\mathrm{Tg} \mathrm{C})\end{array}$ & 7971 & 7531 & 7736 & 7996 & \\
\hline $\begin{array}{l}\text { Global total emissions, } \\
\text { year } 2005 \text {, common basis }(\mathrm{TgC})^{\mathrm{d}}\end{array}$ & 7253 & 7531 & 7683 & 7358 & \\
\hline
\end{tabular}

a Annex I countries are to report annually, non-Annex I countries have less stringent reporting requirements.

b Does not include the three regions of Other Africa, Other Latin America, and Other Asia which contain data for countries not tabulated separately.

c In global totals, but not in national totals.

${ }^{\mathrm{d}}$ Common basis is an attempt to place all inventories on equal footing. Since the IEA is the least inclusive, their estimate was retained. EIA was recalculated as the EIA value from the line above minus gas flaring (no separate tabulation for non-fuel hydrocarbons is listed). EDGAR was recalculated as the EDGAR value from the line above minus gas flaring minus cement minus non-fuel hydrocarbons. CDIAC was recalculated as the CDIAC value from the line above minus gas flaring minus cement minus non-fuel hydrocarbons.

calcining of limestone and other industrial processes, international bunker fuels (as a memo item and not included in the national total) and non-fuel uses of fossil fuels. All data submissions are publicly available on the UNFCCC website (http://unfccc.int/ghg_data/ghg_data_unfccc/items/4146. php).

The last data line of Table 1 is an attempt to place all of the inventories on a common basis. This was done by including only elements of the respective inventories common to all of them. In this regard, the IEA is the most restrictive so other inventories were modified to fit the IEA reporting categories as noted in Table 1. The average of the four values reported is $7457 \mathrm{Tg} C$ with a standard deviation of $164 \mathrm{Tg} \mathrm{C}$. On this common basis accounting, the three global data sets agree to within $3 \%$ of their average. This agreement is considered remarkable when one understands their different accounting methods and starting data. See Sect. 8 for additional discussion about uncertainties associated with these data.

Due to the similarity of global data sets and the focus in this synthesis on the common message that these data sets provide, Sects. 3, 4, and 5 primarily use CDIAC data for the discussion development. Use of IEA, EIA, or EDGAR data would give similar results and/or conclusions. FFCO2 data reported in this manuscript are generally reported in mass carbon units; to calculate mass $\mathrm{CO}_{2}$ units, multiply by 3.67 (the ratio of their molecular weights, 44/12).

\section{Global FFCO2 emissions}

\subsection{Global FFCO2 emissions - the overall picture}

Figure 3a shows the global magnitude of the annual FFCO2 emissions with time. The almost ever-increasing magnitude of the curve can be modeled by several equations. For example, a 10x2 Fourier Series polynomial fits the data extremely well although its terms do not have any known descriptive capability of relevant controlling processes. Only a slightly poorer fit is obtained by a simple exponential equation where its terms can be related to gross domestic product (GDP) and efficiency improvements (Raupach et al., 2008, 2007). However, these equations fail to capture the short term decreases in year-to-year values when they occur (e.g., the 1930s depression, the 1945 end of World War II, the 1980s recession) and the year-to-year variability generally. Thus, for the historical record, the actual emission values are preferred in scientific studies. For projecting emissions into the near future, fit equations could be used (if one assumes the absence of major trend changes). For longer terms, projections are generally based on assumptions regarding economic, technological, and population growth (e.g., Nakicenovic et al., 2000).

Figures 1a and 3a show that FFCO2 from each of the major fuel sources has grown over time. Coal was the dominant global energy source from 1750 to 1950 and continues to grow in use. FFCO2 emissions from liquid fuels first surpassed those from coal in the late 1960s and now emissions from the two are similar (more than $3000 \mathrm{Tg} \mathrm{C}$ annually). Increased global utilization of natural gas since 1950 is evident in the global FFCO2 record. Growth and economic development have resulted in increased cement production 


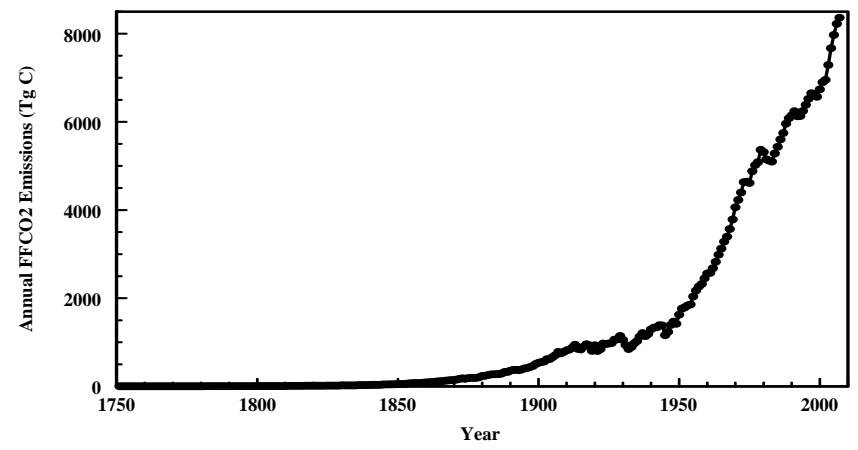

Fig. 3a. Annual FFCO2 emissions for the years 1751 to 2007. This figure was created from the sum of national production values (see Sect. 1) for 15830 country-year pairs. Data from Boden et al. (2010).

worldwide and, in turn, elevated releases of $\mathrm{CO}_{2}$ from this anthropogenic source as well. A very recent trend is the increasing use of modern biofuels such as bioethanol and biodiesel to replace fossil oil products in road transport. Modern biofuels represented in 2009 and 2010 about $3 \%$ of global road transport fuels (Olivier et al., 2011; Olivier and Peters, 2010). Although $\mathrm{CO}_{2}$ emissions from biomass-based fuels are expected to continue increasing, they are not fossil fuels and thus not included in FFCO2 estimates.

Figure $3 b$ shows the annual growth in FFCO2 emissions with time (i.e., the first derivative with respect to time of the curve in Fig. 3a). The importance of this figure is twofold: (1) despite variability, emissions are increasing with time (the average change is $33 \mathrm{TgC}$ per year over the 256 years shown), and (2) while the acceleration in emissions (i.e., the second derivative with respect to time of the curve in Fig. 3a, figure not shown) may appear visually to be increasing with time, statistically ( $p=0.05$ level) that acceleration is not significantly increasing with time. Instead, the large variability seen in more recent years of the time series is growing along with the overall magnitude of emissions (as seen in Fig. 3a). For example, the year 2003 to 2004 increase of nearly $400 \mathrm{Tg} \mathrm{C}$ represents less than $5 \%$ of the 2004 total.

The cumulative emissions from $\mathrm{FFCO} 2$ activities are shown in Fig. 3c. From the year 1959 to the year 2008, an average of $43 \%$ of these emissions remained in the atmosphere and were not removed by the terrestrial biosphere or oceans (Le Quéré et al., 2009). Rafelski et al. (2009) model this long term airborne fraction at $57 \%$. It is this transfer of carbon from geologic reservoirs to the atmosphere which is the primary driver of modern day concerns regarding climate change. Figure $3 \mathrm{c}$ also highlights the sustained growth of FFCO2 emissions and that more than $50 \%$ of FFCO2 has been emitted since 1980 .

Table 2a shows the trends in individual national FFCO2 emissions over different time periods for countries that existed with consistent statistics for the begin and end dates listed in the table. Note that some countries exist at the begin

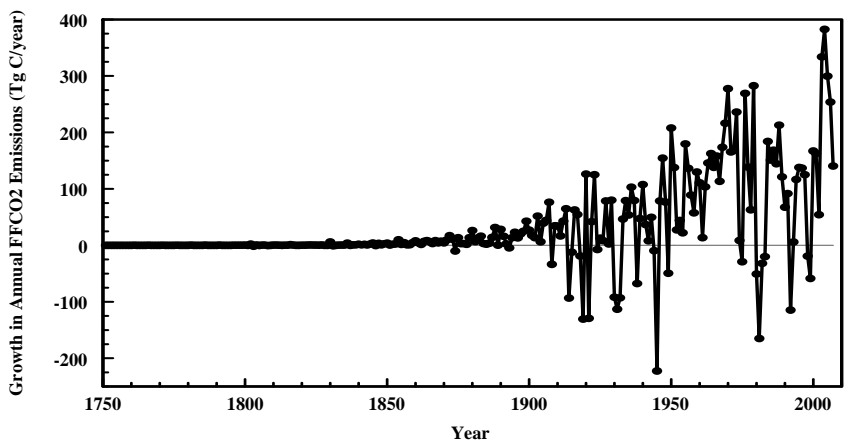

Fig. 3b. Growth of FFCO2 emissions from the year 1752 to 2007. Positive values indicate an increase in year-to-year emissions and negative values indicate a decrease in year-to-year emissions. A gray zero line has been added for reference. Data from Boden et al. (2010).

date but no longer exist at the end date (e.g., USSR, German Democratic Republic). Likewise, some countries exist at the end date but did not exist at the begin date (e.g., Czech Republic, Ukraine). These countries which did not exist for the entire time period are excluded from the statistics in Table 2a. The statistics of Table $2 \mathrm{a}$ are sensitive to the end years chosen, but despite this, the significance of Table 2a is similar to that of Fig. 3a: emissions are increasing with time.

Note that growth is not universal as some of the growth factors are less than unity for some time intervals examined. Growth factors less than one indicate that FFCO2 emissions decreased with time over these time periods. For the begin date of 1950, only the Falkland Islands (Malvinas) had emissions that declined over this time interval. The Falkland Islands had extremely high per capita emissions in the early part of the time series which declined with time due to significantly reduced imports of refined oil. For the begin date of 1980, there are 25 countries who had reduced emissions over this time interval. These countries are located on five continents. There are some notable features of these countries such as nine of them have made commitments/investments in non-fossil-fuel energy technologies such as nuclear power (e.g., France), six of them are former Soviet Union satellite countries (e.g., Hungary), four of them are in Africa (e.g., Gabon), and one has been under constant military engagements (i.e., Afghanistan). Note that despite these reductions in FFCO2 emissions in some countries, overall, the reductions are small relative to global totals and the global total (e.g., Fig. 3a) and global annual average growth (e.g., Fig. 3b) of FFCO2 emissions keeps increasing.

\subsection{Global FFCO2 emissions - sectoral trends}

When global FFCO2 emissions are examined by sector, power generation and industry dominate the total mass of emissions (Fig 3d). Since 1970, power generation and road 


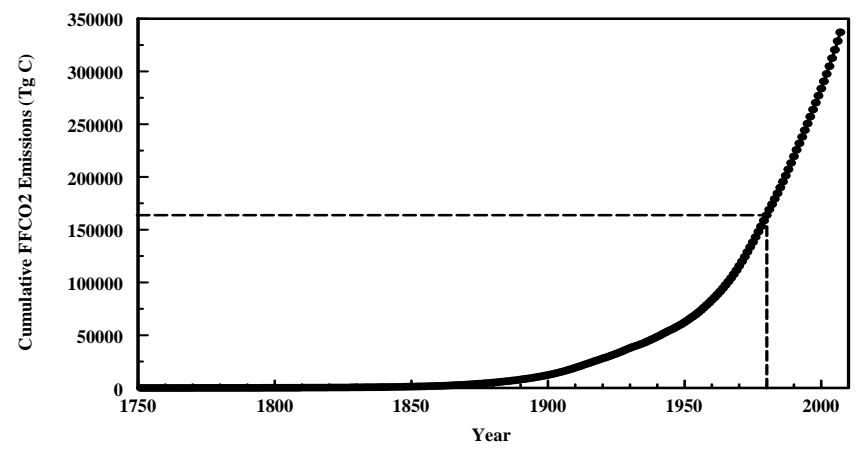

Fig. 3c. Cumulative FFCO2 emissions from the year 1751 to 2007. This figure was created from summing the data in Fig. 3a. The dashed line indicates when approximately $50 \%$ of emissions have been emitted. Data from Boden et al. (2010).

transport are the quickest growing sectors relative to their 1970 emissions.

These sectoral data are generated by the IEA and are a notable feature of IEA and EDGAR data sets. Van Aardenne et al. (2001) have extended the EDGAR sectoral FFCO2 inventory back to 1890 for the main sectors.

Not shown in the aggregated data of Fig. $3 d$ are the differences between mature industrialized countries and developing countries. One notable change with time is the geographical shift in emissions from the (manufacturing) industry sector as it grows in developing countries while in industrialized countries it is increasingly replaced by the service sector (which is less fuel intensive).

\subsection{Global FFCO2 emissions - through Kyoto eyes}

Emission inventories allow us to ascertain the effectiveness of current international agreements that have the goal of "stabilization of greenhouse gas concentrations in the atmosphere at a level that would prevent dangerous anthropogenic interference with the climate system" (UNFCCC, 1992) by limiting emissions to the atmosphere. While the agreements do not focus solely on FFCO2 (KP, 1998), FFCO2 is a major component in obtaining treaty objectives. Furthermore, it is generally accepted that FFCO2 emissions must be reduced to stabilize atmospheric concentrations.

To examine the effect of these international agreements, figures similar to Fig. 3a, b, and c will be presented but with the data disaggregated by countries who have pledged treaty commitments (i.e., Annex B countries) and those who have not (i.e., non-Annex B countries). Most commitments are reductions below a baseline emission level, but not all commitments are reductions (KP, 1998).

Figure 3e is similar to Fig. 3a except that FFCO2 emissions are further categorized by Kyoto Protocol status. The black curve includes all countries who have pledged emissions limitations. The gray curve includes all countries where energy data and emission estimates exist but who have not

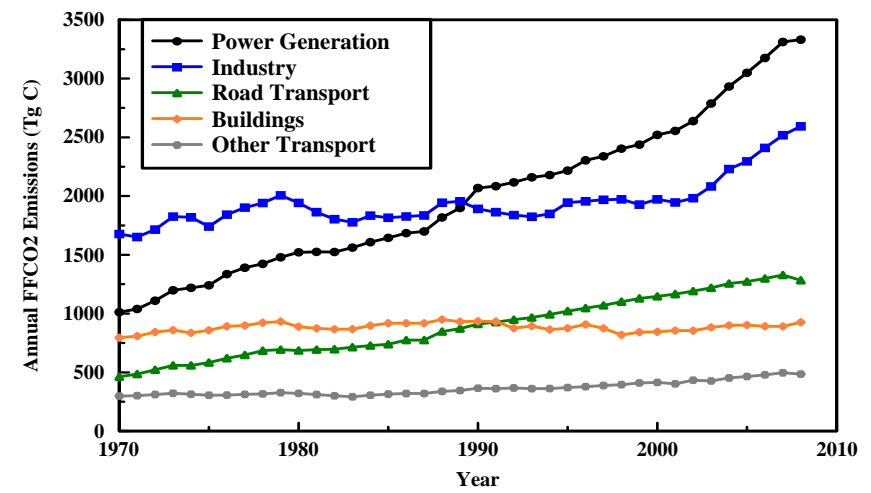

Fig. 3d. Sectoral FFCO2 emissions from the year 1970 to 2008 . Data from EDGAR 4.2 (EC-JRC/PBL, 2011).

pledged emissions limitations. The curves cover years 1751 through 2007 and give a historical perspective to national emissions. The Kyoto Protocol years of interest include a 1990 base year with emissions limitations to be reached between the years 2008 and 2012. These years are a subset of the data shown in Fig. 3e. Two important observations can be seen in Fig. 3e. First, regardless of Annex B status, and as with Fig. 3a, FFCO2 emissions are generally increasing with time. Second, the annual emissions from non-Annex B countries now exceed those from Annex B countries. This is in stark contrast to emission patterns when the Kyoto Protocol was negotiated.

Figure $3 \mathrm{f}$ is similar to Fig. $3 \mathrm{~b}$ except that FFCO2 emissions are further categorized by Kyoto Protocol status. The black curve includes all countries who have pledged emissions limitations. The gray curve includes all countries who have not pledged emissions limitations. Figure $3 \mathrm{f}$ shows the annual growth in FFCO2 emissions with time (i.e., the first derivative with respect to time of the curves in Fig. 3e). The importance of this figure is twofold: (1) despite variability, emissions are increasing with time (the average change over the 256 years shown in Fig. $3 \mathrm{f}$ is $15 \mathrm{Tg} \mathrm{C}$ per year for Annex $\mathrm{B}$ countries and $17 \mathrm{Tg} C$ per year for non-Annex B countries), and (2) while the acceleration in emissions (i.e., the second derivative with respect to time of the curves in Fig. 3e, figure not shown) may appear visually to be increasing with time, statistically ( $p=0.05$ level) that acceleration is not significantly increasing with time. Instead, the large variability seen in more recent years of the time series is growing along with the overall magnitude of emissions (as seen in Fig. 3e), and much of the year-to-year variability is in non-Annex B countries.

Figure $3 \mathrm{~g}$ is similar to Fig. $3 \mathrm{c}$ except that cumulative FFCO2 emissions are further categorized by Kyoto Protocol status. The black curve includes all countries that have pledged emissions limitations. The gray curve includes all countries who have not pledged emissions limitations. In terms of cumulative emissions, the Annex B countries have 


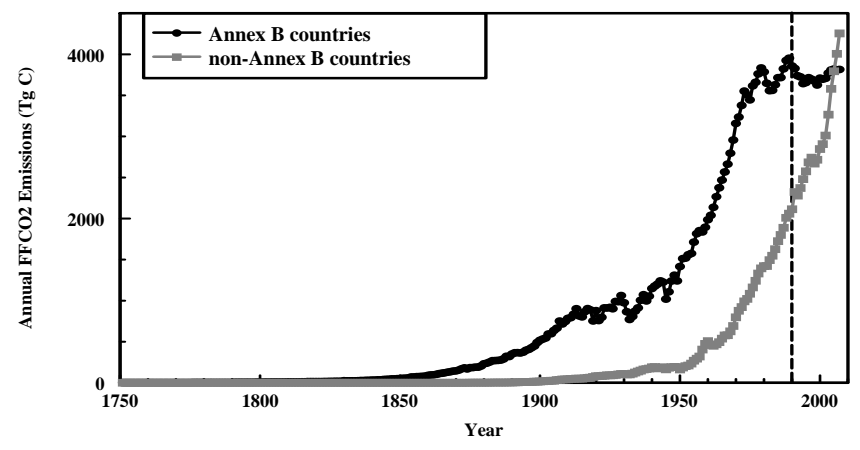

Fig. 3e. Annual FFCO2 emissions for the years 1751 to 2007, disaggregated by Kyoto Protocol status. Similar to Fig. 3a. This figure was created from the sum of national consumption values (see Sect. 1) for 15830 country-year pairs. For Yugoslavia and the USSR, two countries whose dissolution resulted in some states which signed the Kyoto Protocol and some states which did not sign, pre-dissolution emissions have been proportioned to the first year after dissolution. A dashed vertical line marks the Kyoto protocol base year of 1990. Data from Boden et al. (2010).

emitted about 2.5 times more carbon to the atmosphere than the non-Annex B countries for the time period shown.

Table $2 \mathrm{~b}$ shows the trends in individual national FFCO2 emissions from years 1990 to 2007 for Annex B and nonAnnex B countries. For Annex B countries, the smallest growth factor is recorded for the Ukraine and likely reflects the faltering economy there. The largest growth factor is recorded for Spain with the $58 \%$ growth well above their European Union internal burden-sharing agreement of $15 \%$ growth (which is their national contribution to the overall Kyoto signed and ratified commitment of a European Community $8 \%$ reduction). The US, the largest FFCO2 emitter of the Annex B countries, has a growth factor of 1.20 (the $20 \%$ increase is in contrast to the $7 \%$ reduction commitment signed, but not ratified, in the Kyoto Protocol). The average of Annex-B countries is a $1 \%$ reduction and given the increases over 1990 levels as seen in Fig. 3e, the Annex B countries are not on a linear track to meet their Kyoto target of a 5\% GHG reduction by the 2008 to 2012 commitment period. However, using data that extends temporally beyond that in Fig. 3e to include the years 2008 and 2009 which includes the time of the global financial crisis, Olivier et al. (2011) conclude that the Annex B countries may meet their Kyoto target of a $5 \%$ GHG reduction by the 2008 to 2012 commitment period. This summary excludes reductions in non-FFCO2 emissions and GHG reductions purchased from Clean Development Mechanism projects in non-Annex B countries, as allowed for by the Kyoto Protocol.

For non-Annex B countries (Table 2b), the smallest growth factor is recorded for the Republic of Moldova, and similar to the Ukraine above, this likely reflects the faltering economy. The largest growth factor is recorded for Namibia (495.63, although this may be a statistical aberration), fol-

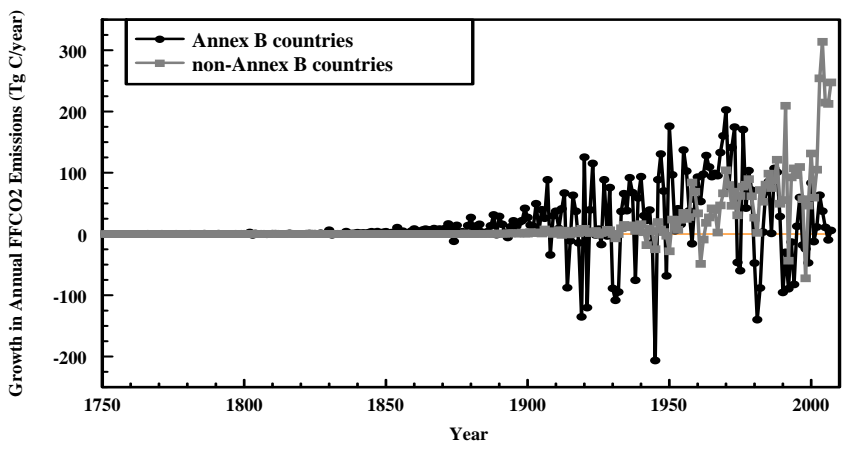

Fig. 3f. Growth of FFCO2 emissions from the year 1752 to 2007 , disaggregated by Kyoto Protocol status. Similar to Fig. 3b. Positive values indicate an increase in year-to-year emissions and negative values indicate a decrease in year-to-year emissions. An orange zero line has been added for reference. Data from Boden et al. (2010).

lowed by Equatorial Guinea (40.07), Somalia (32.82), Cambodia (9.84), and Laos (6.60). China, a non-Annex B country and the largest FFCO2 emitter in the world, has a growth factor of 2.66. The average growth for non-Annex B countries is more than a $400 \%$ increase (equal country weighted) and explains much of the large growth in emissions seen in Fig. 3a and e (with the majority of this growth from China on a mass-basis).

The important message from Table $2 b$ is similar to the message of Fig. 3a: emissions are increasing with time. Note, again, this growth is not universal as a few growth factors are less than unity. These growth factors less than one indicate that 2007 FFCO 2 emissions were less than FFCO2 emissions in 1990. There are 20 Annex-B countries with growth factors less than one and 23 non-Annex B countries with growth factors less than one. While economic hardships can explain some of these growth factors, it is not the sole explanation. Deliberate policy actions have reduced FFCO2 emissions in some countries. Also, the reunification of Germany and the switch from coal to natural gas in the United Kingdom and Germany have resulted in decreases in FFCO2 emissions. Future policy actions may want to target the electricity generation and the transport sectors for future $\mathrm{FFCO} 2$ reductions. The IEA Sectoral Approach shows that between 1971 and 2008, emissions from these sectors increased from one-half to two-thirds of total global emissions.

Figure $3 \mathrm{e}, \mathrm{f}$, and $\mathrm{g}$ and Table $2 \mathrm{~b}$ give a sense of the annual, growth of, and cumulative FFCO2 emissions, subdivided by Kyoto Protocol status. Along with analogous Fig. 3a, b, and $c$, and Table 2a, these measures have been given as global totals because in terms of atmospheric radiative effects, it does not matter from which individual country emissions originated. The mixing time of FFCO2 in the atmosphere is relatively short compared to its lifetime. Thus, it does not matter if a molecule of FFCO2 originates from the US, China, or Zimbabwe - its effect on atmospheric radiative effects is the 


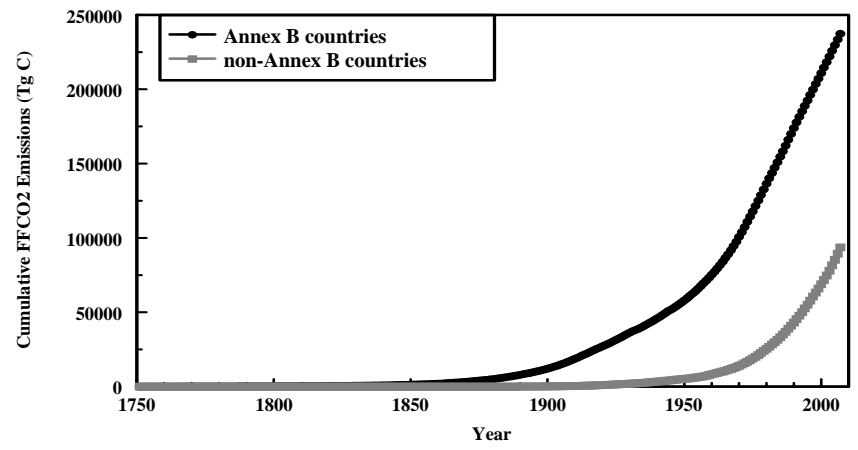

Fig. 3g. Cumulative FFCO2 emissions for years 1751 to 2007, disaggregated by Kyoto Protocol status. Similar to Fig. 3c. This figure was created from summing the data in Fig. 3e. Data from Boden et al. (2010).

same. It is the total quantity of $\mathrm{CO}_{2}$ in the atmosphere which is of ultimate concern to climate change processes.

Note that atmospheric $\mathrm{CO}_{2}$ concentration stands in contrast to some other measures of FFCO2 properties. Carbon intensity is defined as the mass of FFCO2 emissions divided by a unit of GDP (EIA, 2011b, Raupach et al., 2007). By this measure, the US FFCO2 situation is improving as this ratio is decreasing. However, as GDP is generally increasing, this ratio masks the fact that FFCO2 emissions are also increasing. The decreasing ratio implies that the economy is operating more efficiently in terms of FFCO2 emissions. The decreasing ratio does not assure that absolute emissions are decreasing.

\subsection{Global FFCO2 emissions - why care?}

One can consider $\mathrm{CO}_{2}$ emissions not only in terms of annual fluxes but also as cumulative totals (e.g., Fig. 3c and g). One significance of cumulative emissions arises from the relationship between warming above preindustrial temperatures $(T)$ and cumulative anthropogenic $\mathrm{CO}_{2}$ emissions $(Q)$ from fossil-fuel combustion and net land use change since the start of the industrial revolution around 1750. Several recent papers have proposed that the relationship $T(Q)$ is robust and quantifiable within uncertainty bands (Allen et al., 2009; Meinshausen et al., 2009; Zickfeld et al., 2009; Matthews et al., 2009; Raupach et al., 2011).

Figure $3 \mathrm{~h}$ shows the history of annual emissions and cumulative emissions (since 1751) of FFCO2 and carbon emissions from land use change (LUC), together with their sum, the total $\mathrm{CO}_{2}$ emissions from human activities. Annual emissions (left panel of Fig. 3h) are first considered. The past growth trajectories for FFCO2 and LUC emissions are different: LUC emissions have leveled off over the decades since around 1970 and have very likely decreased since around 2000 (Houghton et al., 2012), whereas FFCO2 emissions continue to increase strongly apart from a small recent dip attributable to the global financial crisis (Peters et al., 2011;
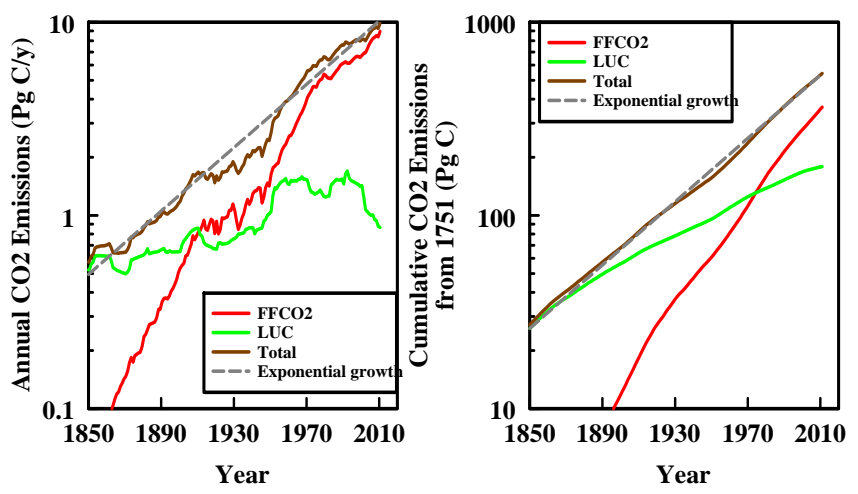

Fig. 3h. Annual and cumulative global $\mathrm{CO}_{2}$ emissions for years 1850 to 2007. Left panel: Annual global $\mathrm{CO}_{2}$ emissions from fossil fuels and other industrial processes including cement manufacture (FFCO2, red), land use change (LUC, green) and total (FFCO2 + LUC, brown). Right panel: Cumulative global $\mathrm{CO}_{2}$ emissions from 1751 , color coded as in left panel. Axes are linear-log so that exponentially growing emissions appear as a straight line. In both panels, the FFCO2 is the same global fuel use data as displayed in Fig. 1b. In both panels, the dashed grey line is a fit to the total $(\mathrm{FFCO} 2+$ LUC) emissions data of an exponential-growth model with a growth rate of $1.9 \%$ per year. This corresponds to a doubling of emissions and cumulative emissions every 37 years. The unit of petagrams carbon $(\mathrm{PgC})$ is equal to $10^{15}$ grams of carbon.

Friedlingstein et al. 2010; Le Quéré et al. 2009). Combining both trajectories, the sum of FFCO2 and LUC emissions has grown almost exponentially, at $1.9 \%$ per year (doubling time $37 \mathrm{yr}$ ), over the period 1850 to 2010.

The corresponding cumulative emissions are shown in the right panel of Fig. 3h. For more than 100 years, the total (FFCO2 + LUC) cumulative emission has grown exponentially at $1.9 \%$ per year, like the annual total emission. The scatter in the total cumulative emission about the exponential-growth line is much less than for annual emissions, because of the smoothing effect of accumulation. The total $(\mathrm{FFCO} 2+\mathrm{LUC})$ cumulative emission to the end of 2009 was about $530 \mathrm{Pg} \mathrm{C}$, rising at nearly $10 \mathrm{Pg} \mathrm{C}$ per year (Le Quéré et al. 2009). Of this total about $350 \mathrm{Pg} \mathrm{C}$ is due to FFCO2 and $180 \mathrm{Pg} \mathrm{C}$ to LUC, but the share of the cumulative total due to $\mathrm{FFCO} 2$ is increasing progressively.

\section{Regional FFCO2 emissions}

Disaggregating global FFCO2 emissions into regional emissions allows disaggregation of the global totals within the context of some regional specificity. From Fig. 4, it is seen that the largest emitting region has evolved over time from Western Europe (WEU) to North America (NAM) to Centrally Planned Asia (CPA). Other regions have risen and fallen relative to their peers over different time frames. For the entire 1751 to 2007 time series, the quantitative order of regional growth rates is mirrored by their qualitative order in 
Table 2a. Basic statistics regarding trends in normalized national FFCO2 emissions for different time periods. $n=$ number of countries which existed at both the beginning and end dates, $\min =\min$ imum annual growth factor for the $\mathrm{n}$ countries (equal country weighted, not weighted by mass per country), med = median annual growth factor, avg = average annual growth factor, $\max =$ maximum annual growth factor. The growth factor is defined as the end date FFCO2 emissions divided by the begin date FFCO2 emissions. A factor of one indicates emissions were equal at the begin and end dates. A factor of two indicates that emissions doubled over the time period. It should be noted that available data for gas flaring and cement production vary by country. In some cases, inclusion of FFCO2 from these sources is sizable (e.g., gas flaring for Middle Eastern countries in the 1970s). Thus, growth factors may also reflect new sources (e.g., there is no gas flaring data in 1900, but it does occur in many countries in 2007. Thus, the 1900-2007 growth factor statistics includes the addition of gas flaring.). Data from Boden et al. (2010).

\begin{tabular}{lcccccc}
\hline $\begin{array}{l}\text { Begin } \\
\text { Date }\end{array}$ & $\begin{array}{c}\text { End } \\
\text { Date }\end{array}$ & $n$ & Min & Med & Avg & Max \\
\hline 1900 & 2007 & 33 & 1.28 & 31.99 & 161.21 & 2469.23 \\
1950 & 2007 & 126 & 0.21 & 18.19 & 43.71 & 403.08 \\
1980 & 2007 & 175 & 0.27 & 2.16 & 3.29 & 82.24 \\
\hline
\end{tabular}

2007 with CPA being the largest and Germany (GER) being the smallest. Different time periods could have dramatically different absolute and relative growth rates associated with them.

Regionally disaggregated emissions serve as essential inputs to integrated assessment models (which can be used to examine the policy-economy-climate interrelationships). These models simulate global energy systems, resource consumption, and socioeconomic development scenarios for the next century for multi-country regions. Emissions are calibrated to historical data and then simulated using different scenarios for the future (e.g., Belke et al., 2011; Sadorsky, 2011; Apergis and Payne, 2009).

The regional designations shown in Fig. 4 are a relic of Cold War politics and, to a lesser degree, of geopolitical and corresponding data reporting changes. While maybe not as politically relevant today, the historical UN regional definitions still serve the regional specificity purpose (e.g., NAM is North America and WEU is Western Europe). However, even WEU is not as clear as it could be. In 1994, CDIAC created a new regional entity, GER. GER incorporated the Federal Republic of Germany (from WEU) and the German Democratic Republic (from Centrally Planned Europe, CPE). The reunited Germany did not fit easily within WEU or CPE. CPA, Centrally Planned Asia, is no longer a faithful description of China and Mongolia, but it still provides a useful grouping for examining the evolution of emissions over time.

Ultimately, one would want regional groupings that reflect something of importance to the task currently at hand (e.g., Fig. 3e, 3f, and 3g used Annex B and non-Annex B coun-
Table 2b. Basic statistics regarding trends in normalized national FFCO2 emissions for Annex B and non-Annex B countries from years 1990 to 2007. $n=$ number of countries, min = minimum annual growth factor for the $\mathrm{n}$ countries (equal country weighted, not weighted by mass per country), med $=$ median annual growth factor, avg = average annual growth factor, $\max =$ maximum annual growth factor. The growth factor is defined as the year 2007 FFCO2 emissions divided by the year 1990 FFCO2 emissions. For some countries proportional emissions were used in 1990 or 2007 as the countries were disaggregated (e.g. former Soviet Union) or aggregated (e.g., Yemen). Thirteen non-Annex B countries (all relatively small FFCO2 emitters, the largest equal to less than $0.2 \%$ of the sum of countries total FFCO2 emissions) were excluded from the analysis because the 1990 data year FFCO2 emissions data were incomplete or missing. Data from Boden et al. (2010).

\begin{tabular}{lccccc}
\hline $\begin{array}{l}\text { Kyoto } \\
\text { status }\end{array}$ & $n$ & Min & Med & Avg & Max \\
\hline $\begin{array}{l}\text { Annex B } \\
\text { non-Annex B }\end{array}$ & 168 & 0.20 & 1.79 & 5.37 & 495.63 \\
\hline
\end{tabular}

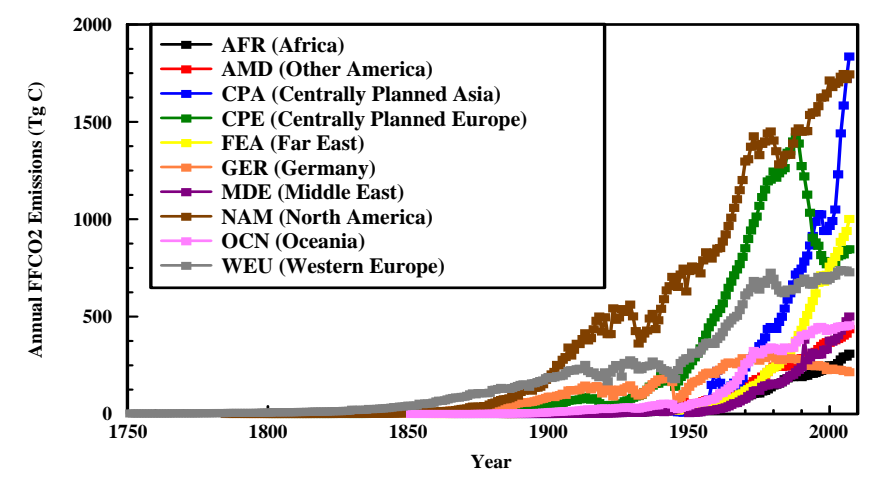

Fig. 4. Regional FFCO2 emissions for the years 1751 to 2007. This figure was created from the sum of national consumption values (see Sect. 1) for 15830 country-year pairs. See Boden et al. (2010) for which countries are included in each region. Data from Boden et al. (2010).

try groupings). No single description of regional groupings captures perfectly the geopolitical and economic changes in recent centuries. However, for the purposes of this synthesis, the historical CDIAC regional groupings serve as a useful example.

\section{National FFCO2 emissions}

National and annual FFCO2 emissions are the basic unit of global FFCO2 emissions. It is at national and annual scales that most energy statistical data are collected by national statistical offices, agencies and/or energy ministries or amassed by centralized energy statistics efforts (e.g., UNSO). The richness and quality of national energy statistics have improved with time. These national and annual data are then 


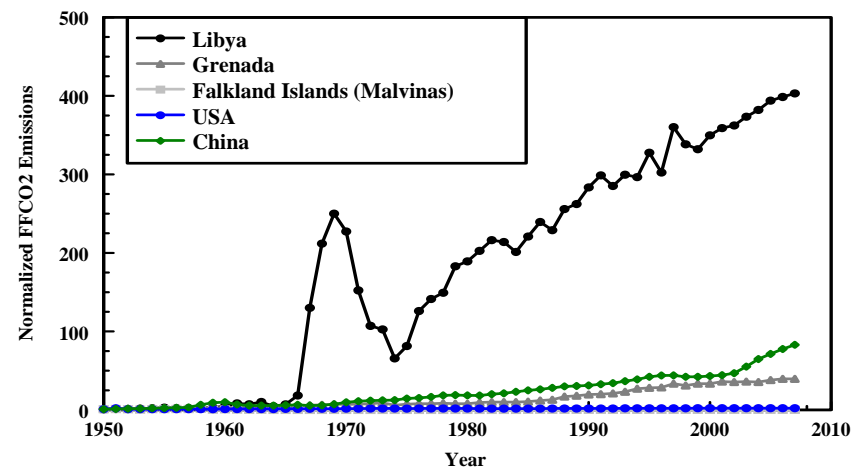

Fig. 5. Normalized national FFCO2 emissions for the years 1950 to 2007. This figure was created from the national consumption values (see Sect. 1) and then normalized to 1950 emissions so that each country has a relative FFCO2 emission value equal to one in 1950. The US curve lies nearly on top of that from the Falkland Islands. Data from Boden et al. (2010).

aggregated for regional (e.g., Sect. 4) or global (e.g., Sect. 3) summaries. These national and annual data can also play a role when looking at finer spatial (e.g., Sect. 5.1) and temporal (e.g., Sect. 5.2) scales.

Figure 5 shows relative $\mathrm{FFCO} 2$ emission histories for five selected countries to illustrate some of the FFCO2 emission trajectories since 1950. These histories were each normalized to 1950 national FFCO2 emissions. Histories were constructed from the 11060 country-year pairs that exist in the data set from 1950 to 2007 which are distributed amongst 246 countries. Some countries were excluded from Fig. 5 for the following reasons: (1) they did not exist in 1950 (e.g., Azerbaijan, 86 countries total); (2) they did not exist in 2007 (e.g., USSR, 23 countries total); (3) they included incomplete or odd data during the years 1950 to 2007 (e.g., Botswana, six countries total); and (4) their 1950 FFCO2 emissions were less than $0.001 \mathrm{TgC}$ (e.g., Vanuatu, nine countries total). These deletions left 122 countries for possible display in Fig. 5.

Figure 5 shows normalized data curves representing the full range of relative growth curves as well as some other features of the data. Libya has the largest relative growth over this time interval (from $39 \mathrm{Tg} \mathrm{C}$ in 1950 to $15600 \mathrm{Tg} \mathrm{C}$ in 2007, a growth factor of 403). Grenada represents the average relative growth over this time interval (from $1.7 \mathrm{TgC}$ in 1950 to $66 \mathrm{TgC}$ in 2007 , a growth factor of 40). The Falkland Islands has the smallest relative growth over this time interval (from $75 \mathrm{TgC}$ in 1950 to $16 \mathrm{Tg} \mathrm{C}$ in 2007 , a growth factor of 0.21 ). Two additional curves represent the two largest FFCO2 emitters in 2007. The curve for the US (from $692124 \mathrm{TgC}$ in 1950 to $1591756 \mathrm{Tg} \mathrm{C}$ in 2007, a growth factor of 2) lies nearly on top of that from the Falkland Islands. The curve for China (from $21465 \mathrm{Tg} \mathrm{C}$ in 1950 to $1783029 \mathrm{Tg} \mathrm{C}$ in 2007, a growth factor of 83) lies slightly above that from Grenada.

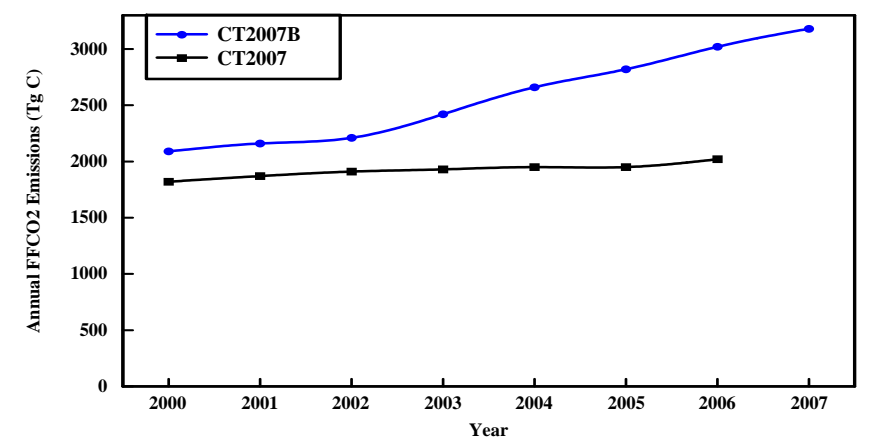

Fig. 6a. Comparison of FFCO2 emissions from two CarbonTracker (CT) simulations for the CT Euarasia temperate region. FFCO2 emissions were revised and updated between the two CT simulations. Data from Jacobson (unpublished data).

All the other 117 countries with complete data from 1950 to 2007 lie in between Libya and the Falkland Islands. Not all curves are monotonic as the bottom two curves suggest. Rather, some curves have strong departures from monotonicity as seen in the Libya curve.

While national and annual scale data are sufficient for many purposes, finer resolution data are often needed to provide a process-based understanding of the global carbon cycle and to motivate and evaluate efforts to control FFCO2 emissions. General circulation models for climate change could utilize emissions data on a latitude-longitude grid at spatial resolutions much higher than that of nations. Flux inversion models benefit from much higher resolution of emissions than what is currently available in the national inventories (Gurney et al., 2002), to provide the best possible prior estimates, especially because FFCO 2 emissions are usually held fixed in inversions (i.e., un-optimized, see Enting et al. (1995) for an exception to the usual practice). Additionally, high resolution data sets of emissions give more information on how specific human activities affect the carbon cycle and can allow for decision makers to better target the most economic ways to reduce emissions from human sources. The next two subsections of section 5 briefly discuss subnational and sub-annual FFCO2 data sets.

\subsection{Sub-national FFCO2 emissions}

Data on sub-national (e.g., state, province, county, city, highway, large point source) FFCO2 emissions are not very common. Data at this level are usually collected for very specific purposes and may not be available for all types of fossil-fuel consumption. Such data are also not always made publicly available for commercial competitiveness reasons. Despite these restrictions, there are data available at the sub-national spatial scale for some countries. Oftentimes, these data are not as detailed or complete as the national data, but insights can be made. Section 6 of this paper describes efforts to display FFCO2 emissions data on a latitude/longitude grid. This 


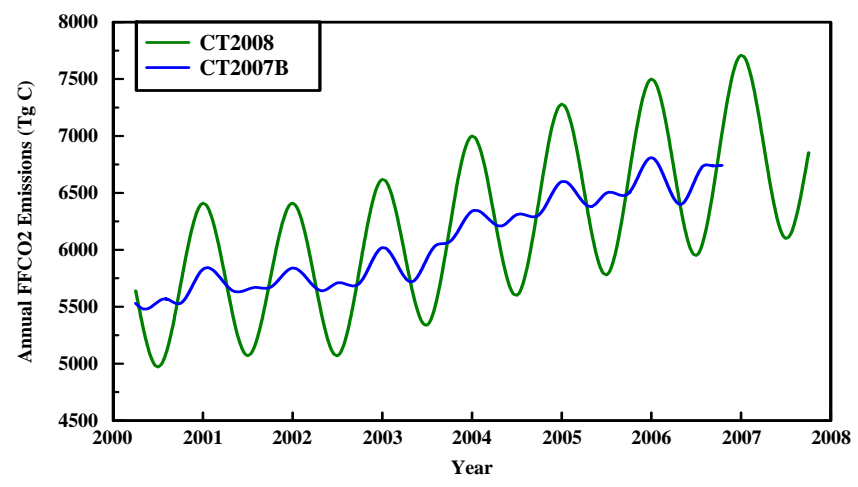

Fig. 6b. Comparison of FFCO2 emissions from two CT simulations for the CT Northern Land region (between $30^{\circ} \mathrm{N}$ and $60^{\circ} \mathrm{N}$ ). The first CT release, CT2007B, includes seasonality for North America only (the remainder of the globe used a smooth curve without seasonality). The latter CT release, CT2008, includes seasonality for all land masses. The two curves differ only in the seasonality imposed on the annual totals (see manuscript text for details on the seasonality imposed). The imposition of seasonality to the annual fluxes preserved the exact same annual totals in both schemes. Data from Jacobson (unpublished data).

section concentrates on the creation of sub-national FFCO2 data without regard to its eventual display.

In the process of looking at sub-annual data, Andres and colleagues have also collected data on sub-national scales for the US (Gregg et al., 2009; Gregg and Andres, 2008), Canada (Gregg et al., 2009), China (Gregg et al., 2008), and Brazil (Losey et al., 2006). Blasing et al. (2005a) have also looked at sub-national US FFCO2 emissions. Gurney et al. (2009) looked at the continental US but approached it from a process-based, bottom-up procedure quite different than the methods taken by Gregg et al. (2009), Gregg and Andres (2008), and Blasing et al. (2005a). This processbased approach often uses statistics at varying spatial scales that can be resampled to varying sub-national spatial scales. Portions of Europe have been similarly examined by Pregger et al. (2007). There are also several sub-national efforts that focus on a particular country that have been displayed at national and international meetings recently; these studies are usually limited to one country or region, performed by groups within that country or region, and often incorporate local knowledge not easily accessible from outside the country or region. Interest in climate change has also created inventories at the corporate, factory, and city scale (e.g., NYC, 2010). Internet-based tools exist for households to estimate their FFCO2 emissions (e.g., http://epa.gov/climatechange/ emissions/ind_calculator.html). At the present time, it is often difficult to reconcile these corporate, factory, city, and household FFCO2 inventories with larger sub-national and national inventories. Even for some of the larger efforts, the sum of sub-national FFCO2 inventories does not always

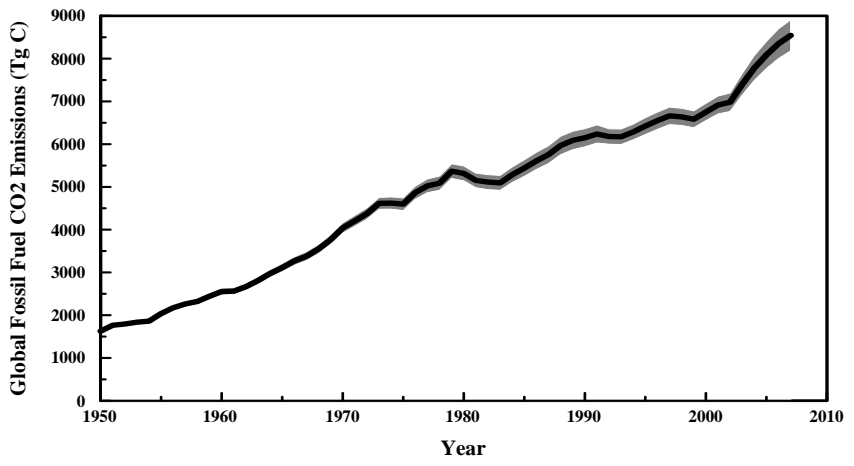

Fig. 7a. Annual FFCO2 emissions for years 1950 to 2007 with the $95 \%$ uncertainty shaded. The shaded area is growing with time because the total magnitude of emissions is growing with time and a growing percentage of emissions are coming from countries with less certainty about their emissions. FFCO2 data from Boden et al. (2010) and uncertainty estimates from Andres (unpublished data).

equal the better known and more certain national FFCO2 inventories.

Another measure of sub-national $\mathrm{CO}_{2}$ is provided by satellites, which can provide snapshots of $\mathrm{CO}_{2}$ concentrations on scales of kilometers to hundreds of kilometers. However, publicly available information from satellites usually does not report FFCO2 fluxes, but rather total atmospheric $\mathrm{CO}_{2}$ concentrations of which FFCO2 is only one part (an exception is Elvidge et al. (2009) who have quantified gas flaring FFCO2 emissions from satellite observations using a night light index). Other contributors to atmospheric $\mathrm{CO}_{2}$ concentrations include recent oceanic fluxes, recent biospheric fluxes, and older background (e.g., older fossil, oceanic, and/or biospheric) fluxes. Data from satellites can be combined in models with emission inventories to calculate $\mathrm{CO}_{2}$ fluxes. However, the most common use today of these models is to calculate fluxes of other components of the global carbon cycle, especially biospheric fluxes, as usually the lowest uncertainties with the input data sets are associated with FFCO2.

\subsection{Sub-annual FFCO2 emissions}

Data on sub-annual (e.g., season, month, week, day, hour) FFCO2 emissions are even less common than those for sub-national FFCO2 emissions. Data at this temporal level are again usually collected for very specific purposes and are rarely available for all types of fossil-fuel consumption. Similar to sub-national data, sub-annual data are also not always made publicly available for commercial competitiveness reasons. Despite these restrictions, there are data available at sub-annual temporal scales. Often, these data are not as detailed or complete as the annual data, but insights can be made. Because of a lack of energy-consumption data, most of the data at fine 
temporal scales is derived from models and limited sampling. In the US, major point-sources of emissions, such as power plants, do have in-stack monitors and report emissions in hourly time steps (http://camddataandmaps.epa. gov/gdm/index.cfm?fuseaction=prepackaged.select). Pétron et al. (2008) created a high resolution (both spatial and temporal) inventory of these power plant emissions.

Andres and colleagues have focused much effort on examining FFCO2 emissions at monthly time scales. To account for the lack of data that give complete coverage of all fossilfuel consumption at monthly time scales in a given country, their approach has mostly been proportional whereby they examine a large fraction of fossil-fuel use at monthly time scales, and then extend that known fraction to the rest of the fossil-fuel stream. Gregg and Andres (2008) discuss the strengths and weaknesses of this approach. Published monthly time series exist for Brazil (Losey et al., 2006), Canada (Gregg et al., 2009), China (Gregg et al., 2008), Mexico (Gregg et al., 2009), and the US (Gregg et al., 2009; Gregg and Andres, 2008). Combining those monthly time series with many others so that approximately $80 \%$ of global FFCO2 emissions are explicitly known at the monthly time scale, Andres et al. (2011) use a proportional-proxy methodology to examine global, monthly FFCO2 emissions. They conclusively show that the global, monthly FFCO2 consumption is significantly distinct from a uniform, flat, annual distribution.

Blasing et al. (2005b) used a similar statistics-based approach for modeling monthly $\mathrm{FFCO} 2$ consumption in the US. The process-based models of Gurney et al. (2009) for the US and Pregger et al. (2007) for Europe incorporate data streams of varying temporal resolution. The output from these models can be resampled at varying time scales of minutes to days to longer time periods with better certainty known about some fossil-fuel consumption sectors than others at the varying temporal resolutions.

\section{FFCO2 inventory distributions}

FFCO2 inventories, as discussed in the previous sections, are most commonly constructed as a series of national tables. While this format has useful properties for many applications, it fails at delivering a view of the FFCO2 emissions in a geographically distributed manner. Data tables are also not easily accommodated by most modern mathematical models that seek to follow the flows of carbon from source to sink. These models most commonly require FFCO2 emissions to be distributed across the Earth's surface at spatial resolutions similar to the atmospheric transport/climate models employed. This process of going from tables to maps requires two steps: (1) selection of a mapping projection, and 2) selection of a methodology to distribute FFCO2 from data tables to that map projection. Several attempts have been made to map FFCO2 emissions. Each has its own strengths and weaknesses. Following is a description of some of these attempts.

\subsection{Map projections}

Selection of a map projection is commonly determined by the underlying border data set to which the $\mathrm{FFCO} 2$ emissions will be mapped. At present, two-dimensional (e.g., surface) maps are more common than three-dimensional maps (which include altitude). Two-dimensional maps cannot accommodate shape, area, distance, and direction with equal fidelity. The process of going from a three-dimensional world to a two-dimensional surface distorts at least one of these aspects. Mathematical transformations exist to translate between various map projections. This topic is important for those who ingest FFCO2 inventories into mathematical models which have a map projection built into them which does not conform to the FFCO2 inventory distribution map projection. For some purposes it might also be useful to recognize that all emissions do not necessarily occur at the surface of the Earth. Emissions are discharged from tall smoke stacks, from airplanes, and at high temperatures that will generate rising plumes.

\subsection{Distribution methodologies}

There are many existing methodologies to convert tabular data to a (two-dimensional) distribution surface. Each has strengths and weaknesses for various applications. Most involve some proxy variable or variables whose distribution is better known than the native resolution of the FFCO2 inventory data. For process-based inventories (e.g., Olivier et al., 2011, 2005b; Pregger et al., 2007; Gurney et al., 2009), process data usually take the spatial role of the proxy variable. Both approaches, proxy variable or process-based, need to concern themselves with both spatial and temporal fidelity in representing FFCO2 emissions on the distribution surface. The evaluation of these distribution methodology attempts is further compounded by the lack of physical, independent measurements of FFCO2 emissions at the spatial and temporal scales used by the distribution methodologies.

The following four subsections summarize the major attempts to map FFCO2 inventories on two-dimensional surfaces. While the discussion is largely chronological, the approaches have been grouped by categories.

\subsubsection{Proxy approaches}

Andres et al. (1996) and Brenkert (1998) distribute national FFCO 2 emission estimates on a $1^{\circ}$ latitude by $1^{\circ}$ longitude grid by using population density maps, assuming that per capita emissions are equal within each country. This approach allowed Andres et al. (1996) to observe that a large portion of global emissions came from the northern developed countries and that the latitudes of the peak and median of emissions were both moving south as time progressed. The 

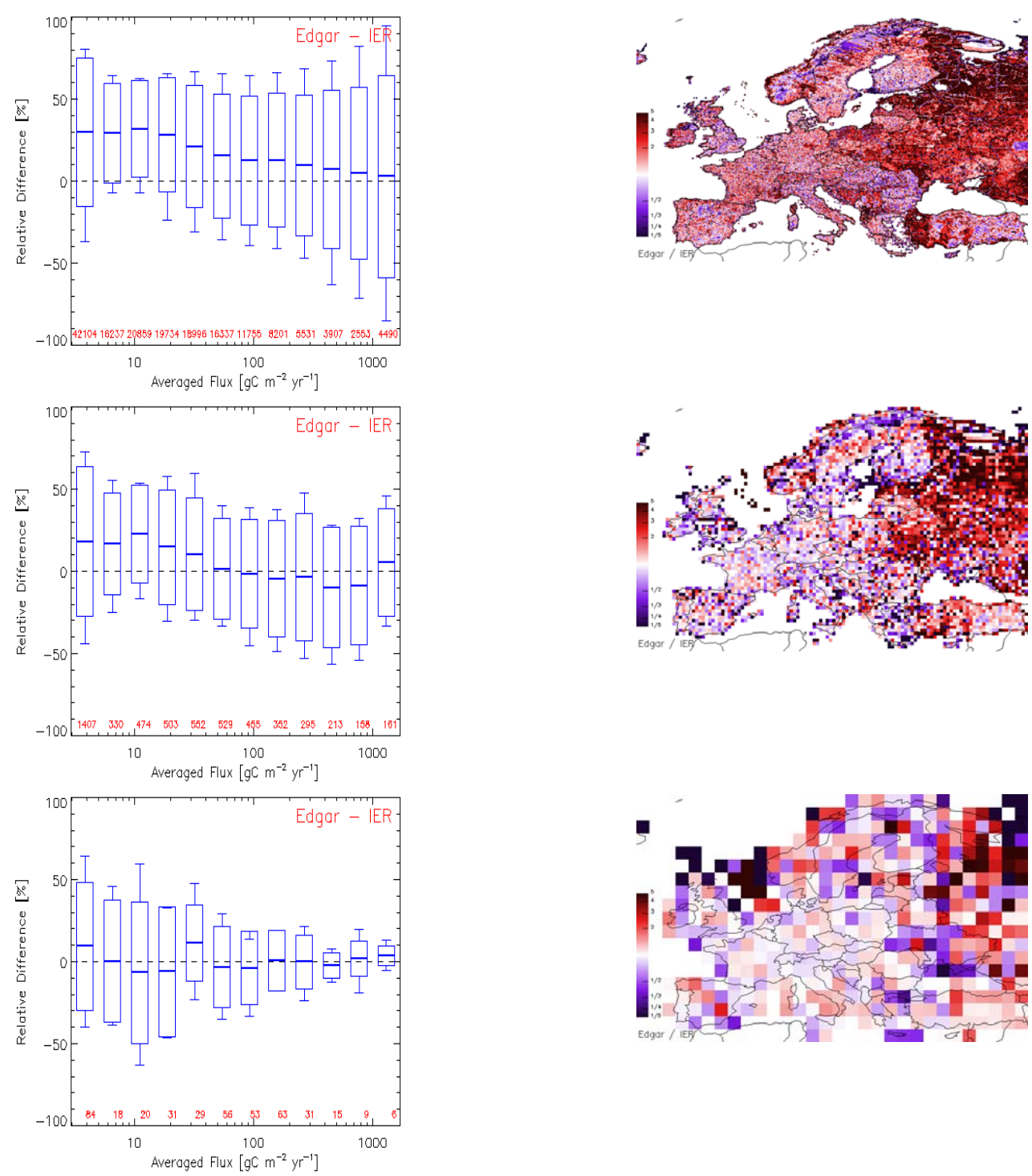

Fig. 7b. Comparison between EDGAR and IER fossil fuel emissions $\left(\mathrm{g} \mathrm{C} \mathrm{m}^{-2} \mathrm{yr}^{-1}\right)$ at various spatial resolutions (top to bottom: 1/12, 1/2, and 2 degrees). The right column shows the ratio of EDGAR 4.1 to IER emissions (log scale). The left column shows the binned relative difference $(a-b) /(a+b)$ where $a$ is the EDGAR estimate and $b$ is the IER estimate. The thick horizontal line is the mean, the box indicates \pm one standard deviation, and the whiskers indicate the $10 \%$ and $90 \%$ percentiles. Perfect agreement would have the mean and standard deviation equal to zero.

Andres et al. (1996) approach has been used to map emissions from 1751 to the present. One advantage (and disadvantage) of their constant population proxy is that changes observed in the maps are due solely to changes in national emissions, not to population shifts within each country. Blasing et al. (2005a) showed that population density could function as a first order approximation for the sub-national distribution of FFCO2 emissions within countries, but that there are situations where the population density proxy has limitations (e.g., when coal is consumed in sparsely populated areas to produce electricity that is transmitted to more populated areas). Rayner et al. (2010) show that the population-
FFCO2 correlation becomes weak as spatial scales shrink to sub-national scales as regional and local sources (such as point sources and line sources) become more important. Thus, population data have difficulties in high-spatial resolution mapping.

EDGAR (Olivier et al., 2005b) took the population proxy approach further by using more than 40 different geographic data sets including sectoral energy consumption data, power plant location, road density, aviation, oil refinery location, as well as urban and rural population densities to estimate the spatial distribution of anthropogenic emissions within each country on a $0.1^{\circ} \times 0.1^{\circ}$ (about $\left.10^{\circ} \times 10 \mathrm{~km}\right)$ grid. This 
approach allows better proxies than population to be used for certain FFCO2 emissions. This approach also allows additional maps to be generated by economic sector (e.g., energy, production of goods and services, residential, road transportation, and aviation). Olivier et al. (2005b) noted that road transportation and electricity generation are major factors in determining the spatial distribution of emissions and that these sectors can develop relatively quickly (e.g., former East Germany, countries of the former Soviet Union, and China in the last decade).

Gurney et al. (2009) also produce sectoral maps, but instead of producing these maps from the top-down approach used previously, compile these maps from a process-based approach. Gurney et al. (2009) contains highly detailed FFCO2 emissions estimates for both point and nonpoint sources in the US, at a spatial scale of less than $100 \mathrm{~km}^{2}$. There is generally close agreement, within a few percent, between national US inventories produced by the EIA and the Gurney et al. (2009) inventory, though there are some discrepancies with non-road transportation due to data limitations for railroads and ships. When compared to the Brenkert et al. (1998) estimates that relied on a population proxy, Gurney et al. (2009) also recognized some major discrepancies in the industrial and utility sector, where large quantities of fossil fuel are consumed away from population centers. While Gurney et al. (2009) give very detailed sectoral, hourly information about emissions at high spatial detail, the inventory is currently limited to the contiguous US and is only complete for the year 2002, though current efforts continue to increase the scope of the inventory. There is also a great deal of extrapolation needed in the approach of Gurney et al. (2009) since process information is not available everywhere.

\subsubsection{Fossil-fuel approaches}

While fossil-fuel approaches were used in section 6.2 .1 by applying national FFCO2 emissions to national political units displayed on a map, the term is used in this manuscript section as a method to distribute sub-national emissions. Essentially the idea is the same, but the spatial scale of application has changed.

Using a bottom-up accounting approach, Blasing et al. (2005a) have produced an annual FFCO2 emissions inventory for the 50 states of the US using state level energy data from the EIA. Such a study is made possible due to the availability of detailed data collected by the EIA, including specific fuel consumption statistics as well as the energy and carbon content of the various grades of fuel delivered to each state. However, this approach is not applicable to countries where such detailed data are not available. Blasing et al. (2005a) showed that per capita emissions differed by an order of magnitude across the various US states (due to various legal, economic, and geographic factors), suggesting limits to using population distribution as a proxy for emissions estimates.
In contrast to the Blasing et al. (2005a) study, Gregg and Andres (2008) used a top-down method, where a subset of the full sub-national data, which did have fine spatial and temporal resolution, was used to estimate the spatial distribution of FFCO2 emissions for the US on a state by state basis. The advantage of this approach was that it was computationally simpler and that it was applicable to other countries where fine scale data availability is limited. The study showed that this top-down method could produce similar results as the bottom-up method, though it was prone to errors in states where there were disproportionately large amounts of fuel consumed for purposes not represented by the monthly data. Nevertheless, in most cases the procedure did provide estimates that were within a few percent of the estimates produced by Blasing et al. (2005a).

The methodology employed in Gregg and Andres (2008), has also been applied to Brazil (Losey et al., 2006), Canada (Gregg et al., 2009), and China (Gregg et al., 2008). For these countries, a bottom-up accounting method would not have been possible due to the lack of available data, so a top-down approach was all that was possible. In Brazil, FFCO2 emission rates also varied spatially due to differing levels of development and population density among the provinces (Losey et al., 2006). In Canada, as with the US, there were large differences between the sub-national provinces/territories in terms of per capita carbon emissions. For example, per capita emissions in Alberta were an order of magnitude higher than the majority of the Canadian provinces due to the large amount of energy resources in $\mathrm{Al}-$ berta. For China, the methodology was expanded to include proxy information (Sect. 6.2.1) on transportation and industrial outputs to account for limitations in the data available from China. In some areas of China, per capita emissions exceeded the global average, and approached levels similar to those in Europe.

\subsubsection{Satellite-based proxy approaches}

Satellite data has also been used to place FFCO2 emissions on distribution surfaces. This proxy approach is separated from the other proxy approaches (Sect. 6.2.1) because of the numerous attempts to use satellite data. Essentially, though, the approach is the same: find a proxy that has a relationship to FFCO2 emissions. With satellites, this proxy approach offers global coverage and frequent updates. It is limited by the duration of the satellite measurements (both in their beginning and their cessation).

Saxon et al. (1997) demonstrated that country's reported emissions from fossil-fuel consumption is correlated to the corresponding night light index from the nighttime composite image taken by the Defense Meteorological Satellite Program (DMSP) Operational Linescan System (OLS) (Imhoff and Elvidge, 2000). Given the typical multi-year lag in producing emissions inventories, Saxon et al (1997) proposed using satellite imagery to create more timely emissions 
estimates for international climate agreements to the UNFCCC. Elvidge et al. $(1997,1999)$ took this approach further to pinpoint human settlements, gas flaring sources, and population centers.

Doll et al. (2000) used the relationship between night lights and FFCO2 emissions to produce a gridded map of emissions. Doll et al. (2000) compared the estimated distribution of emissions from the night lights imagery to that of Brenkert (1998) and found that the within-country spatial correlation was stronger for developed countries than it was for developing countries and centrally-planned economies, particularly central Asian countries that were part of the former Soviet Union. These countries were typically underestimated by the night lights allocation approach.

In an attempt to create more accurate maps that utilize the nighttime imagery, Ghosh et al. (2010) created a number of statistical models to compare the nighttime imagery to the sectoral emissions estimates from Gurney et al. (2009). While the night lights provided a good first order approximation for the distribution of emissions, emissions from the industrial and transportation sectors were typically underestimated (Ghosh et al., 2010).

Rayner et al. (2010) used a combination of the Kaya Identity proxy (population density, economic activity per person, energy intensity of the economic activity, and carbon intensity of the energy) and statistically-corrected night light imagery (to account for saturated night light pixels) to produce a $0.25^{\circ}$ resolution map of global FFCO2 emissions. They found good agreement between the estimates produced from this method and those of Gurney et al. (2009) for the US. However, even with detailed satellite imagery, Rayner et al. (2010) estimated that the per pixel error rate could approach $50 \%$ and that the errors were furthermore not independent, due to the top-down approach (similar in principle to Gregg and Andres (2008), Brenkert (1998) and Andres et al. (1996)) of apportioning emissions to different pixels. Rayner et al. (2010) suggested that the estimates could be improved by incorporating inverse calculations of ${ }^{14} \mathrm{CO}_{2}$ measurements.

In an attempt to improve the spatial estimates of emissions, Oda and Maksyutov (2011) used calibrated night light imagery in combination with worldwide data on large point source emissions (similar to Gurney et al., 2009 and Olivier et al., 2005b) to produce a $1 \mathrm{~km} \mathrm{x} 1 \mathrm{~km}$ map of emissions. Oda and Maksyutov (2011) found that, in general, pixels in China tended to have a higher magnitude of emissions than pixels in the US. This method also had the benefit of reducing error, since the location of point sources could be mapped more accurately. For the US, the estimates of Oda and Maksyutov (2011) were closer to the process-based estimates of Gurney et al. (2009) than were those of Rayner et al. (2010), most likely due to the incorporation of large point sources.

\subsubsection{Satellite-based measurements}

At present, there are no satellites that directly measure FFCO2 emissions. However, existing and planned satellites measure total $\mathrm{CO}_{2}$ in the atmosphere (and other relevant combustion species (e.g., $\mathrm{CO}$ )). All of these satellites give some sort of vertical or slant column $\mathrm{CO}_{2}$ measurement. To calculate $\mathrm{FFCO} 2$ from these measurements requires the use of transport models and other ancillary data. This is not likely to happen soon as our knowledge of FFCO2 inventories is generally more accurate than our knowledge about other carbon fluxes affecting these satellite measurements (Hungerschoefer et al., 2010).

\subsection{Three-dimensional projections}

There have been some attempts to map total FFCO2 inventories onto three-dimensional globes. Andres was involved in one such effort in the mid-1990s as part of a computer visualization exercise. The EDGAR effort has compiled aviation emissions on a $1 \times 1$ degree grid at altitude bands of $1 \mathrm{~km}$ (Olivier et al, 2005b; EC-JRC/PBL, 2011). As mathematical models become more sophisticated and inventory compilers more aware, future FFCO2 inventories will likely be represented not only on two-dimensional surfaces, but also on three-dimensional surfaces. These surfaces will better incorporate FFCO2 emissions from tall stacks and aircraft with their respective emissions occurring in appropriate atmospheric levels, not solely at the surface as is common today. This will become increasingly important as downwind transport of $\mathrm{FFCO} 2$ and all $\mathrm{CO}_{2}$ becomes better integrated into global change science and policy (e.g., Nassar et al., 2010).

\section{Transport of FFCO2 emissions}

Transport of FFCO2 emissions plays a key role in the transition from FFCO2 inventories and their two-dimensional distribution to their three-dimensional importance. After all, FFCO2 flux is not the sole interest, but there is interest also in the impact of this flux downwind from the FFCO2 source. As soon as transport is introduced to give this downwind and vertical picture, $\mathrm{FFCO} 2$ becomes intimately mingled with other sources and sinks of $\mathrm{CO}_{2}$ : primarily $\mathrm{CO}_{2}$ from the oceans and the terrestrial biosphere. The climatic, biological, biogeochemical, and biophysical effects of $\mathrm{CO}_{2}$ in the atmosphere are independent of the $\mathrm{CO}_{2}$ source. Atmospheric sampling of a point, area, or volume includes these multiple $\mathrm{CO}_{2}$ sources (i.e., FFCO2, oceanic, and biospheric). Due to the higher certainty with which FFCO2 fluxes are known, they are often used as a known quantity (e.g., Gurney et al., 2002) from which the relative contributions of oceanic and biospheric influences can be inferred. Therefore, beginning with a reasonable approximation of the $\mathrm{FFCO} 2$ source 
distribution is important in order to match atmospheric observations to model outputs.

The use of chemical transport and data assimilation models (e.g., Erickson et al., 2008; Kawa et al., 2004) allow the distribution of atmospheric $\mathrm{CO}_{2}$ to be computed and compared to observations. Transport of atmospheric $\mathrm{CO}_{2}$ results in a variety of spatial and temporal distributions of $\mathrm{CO}_{2}$ in the atmosphere. These distributions can be used in tandem with observations and models to estimate the surface source/sink relationships of atmospheric $\mathrm{CO}_{2}$. To illustrate these concepts, the role of transported FFCO2 on atmospheric $\mathrm{CO}_{2}$ concentrations within the CarbonTracker (CT) data assimilation framework is discussed next.

In the US National Oceanic and Atmospheric Administration (NOAA) CT $\mathrm{CO}_{2}$ analysis system (http://carbontracker. noaa.gov, Peters et al., 2007), FFCO2 emissions are specified and not optimized by observations. FFCO2 is tracked as a separate tracer in the atmospheric transport model, and the FFCO2 component estimated for each CT observation (along with a similarly fixed contribution from biomass combustion) is essentially pre-subtracted from the observed $\mathrm{CO}_{2}$ mole fraction. The remaining signal is used to optimize ocean and terrestrial $\mathrm{CO}_{2}$ exchange. Over the course of the five CT versions released to date, there have been two significant revisions to imposed FFCO2 fluxes. These revisions have allowed NOAA researchers to study the sensitivity of estimated land and ocean fluxes to details of the imposed FFCO2 emissions.

Between the original CT2007 and subsequent CT2007B release, new CDIAC FFCO2 emissions inventory data became available (including not only the addition of another year of data but also revisions of data from previous years). For the entire period 2000-2005, the global FFCO2 emissions used in CT2007B were higher than those from CT2007. One prominent difference in CT2007B compared to CT2007 was an increase in the estimate of the FFCO2 emissions in Asia (primarily China, Fig. 6a). The new FFCO2 emissions estimate was about $0.75 \mathrm{Pg} \mathrm{Cyr}^{-1}$ higher for the period 2003-2005 compared to the earlier estimate. Given regional $\mathrm{CO}_{2}$ mass balance, the expectation from this change in fixed FFCO2 emission estimates was that estimates of the biospheric fluxes in Asia would shift to a greater sink to compensate for the increased local FFCO2 emissions. However, there was very little impact on the CT estimate of Asian land fluxes, with the temperate Eurasian region seeing an increase in biospheric uptake of only $0.05 \mathrm{PgC}^{-1}$. The remaining signal of increased FFCO2 emissions appears to have been compensated by enhanced biospheric uptake across all extratropical northern hemisphere land regions. Two reasons for this behavior have been suggested. First, the temperate and boreal Eurasian regions are not well constrained by observations, so the FFCO2 signal may be transported across the Pacific without detection. Due to atmospheric mixing along this trajectory, the origin of the $\mathrm{CO}_{2}$ becomes obscured and the inversion system cannot successfully track it back to the source area. Second, the inversion system may not be flexible enough to alter the a priori biospheric fluxes so as to accommodate the higher FFCO2 emissions. In CT, the parameters that are estimated by observations are constrained statistically to remain within certain probability limits. Thus it is possible that the CT system does not allow parameters to change sufficiently to manifest an Asian land biosphere uptake. However, the very small change in land uptake in this region suggests that the CT parameters were not limited by their statistical boundaries. Most likely, these two releases of CT showed that there were not enough observations covering East Asia to "enforce" regional mass balance. It should be noted, however, that these results may not apply to inversions systems using different observational constraints and different optimization methods.

The second significant revision in CT FFCO2 emissions has to do with a change applied between the CT2007B and CT2008 releases. Since the CT2007B release, CT monthly FFCO2 emissions for each pixel have been set to evolve smoothly in time, using a flux-conserving spline interpolation scheme that yields minimal temporal discontinuities while exactly preserving annual total emissions (Fig. 6b). In the CT2007B release, the smooth curve for North America from $30^{\circ} \mathrm{N}-60^{\circ} \mathrm{N}$ was augmented with an estimate of the seasonal cycle of emissions derived from Blasing et al. (2005b). CT2007B FFCO2 emissions over the rest of the globe followed the smooth curve with no seasonality. For CT2008, an estimate of the Eurasian seasonality of FFCO2 emissions (by emissions sector and country) derived from EDGAR (Olivier and Berdowski, 2001) was applied to the remainder of the land between $30^{\circ} \mathrm{N}$ and $60^{\circ} \mathrm{N}$ (Fig. 6b), again while preserving the exact same annual totals. This experiment allowed NOAA researchers to assess the magnitude of northern extratropical FFCO2 seasonality at all observing sites. This experiment was conducted in part because of observed systematic biases in observation residuals from CT2007B, in which CT2007B tended to overestimate atmospheric $\mathrm{CO}_{2}$ in the summer and underestimate atmospheric $\mathrm{CO}_{2}$ in the winter. A working hypothesis for this experiment was that the winter peak in FFCO2 emissions (and the summer trough) ought to act to eliminate some of the seasonal bias with respect to observed $\mathrm{CO}_{2}$ mole fraction in the atmosphere. The experiment showed that seasonality of FFCO2 emissions can account for a few tenths of a ppm of observed atmospheric $\mathrm{CO}_{2}$, depending on the location of the observing site. While this was too small to correct the CT residual bias, it did confirm the expected phase of the resultant seasonal cycle in the atmosphere. Furthermore, the enhanced seasonality of FFCO2 emissions had no statistically meaningful impact on CT estimated fluxes.

Using imposed FFCO2 emissions represents a significant prior assumption in atmospheric models of $\mathrm{CO}_{2}$. These lessons from an ongoing, annually-updated $\mathrm{CO}_{2}$ analysis show that the response of an inversion system to changes in the details of those emissions can be surprisingly complex. 
Indeed, as higher spatial and temporal resolution estimates of FFCO2 emissions are created, the impacts on modeled atmospheric $\mathrm{CO}_{2}$ concentrations become more complicated to interpret. There is some evidence that the amplitude of atmospheric $\mathrm{CO}_{2}$ may be a strong function of the seasonality of anthropogenic FFCO2 emissions and place constraints on interpretations of $\mathrm{CO}_{2}$ fluxes between the terrestrial biosphere and the atmosphere (Erickson et al., 2008). Corbin et al. (2010) come to a similar conclusion that increased spatial and temporal resolution FFCO2 inventories lead to changes in atmospheric $\mathrm{CO}_{2}$ concentrations of approximately $15 \mathrm{ppm}$ in urban areas over short time intervals and more commonly 4 to $6 \mathrm{ppm}$ in broader areas over seasonal time intervals. This is in contrast to Nassar et al. (2010) who found variations on the order of 0.1 to $1 \mathrm{ppm}$ in surface $\mathrm{CO}_{2}$ concentrations due to the switch from annual to monthly FFCO2 inventories in their model. Differing spatial resolutions likely explain some of these differences.

It is anticipated that future FFCO2 inventories will distinguish among FFCO2 emissions originating at the ground level, from tall stacks, and from aircraft. Additionally, it would be possible to incorporate into atmospheric models rising plumes of hot stack gas as has been done in some cases for biomass burning emissions (Freitas et al., 2006). This vertical sensitivity of FFCO2 emission inventories, combined with improved transport modeling, should allow for better matches between computed and observed (i.e., sampled) atmospheric $\mathrm{CO}_{2}$ concentrations. Incorporation of isotopic variations (e.g., ${ }^{13} \mathrm{CO}_{2}$ and ${ }^{14} \mathrm{CO}_{2}$ ) should also improve future matches of computed and observed atmospheric $\mathrm{CO}_{2}$ concentrations.

Another improvement to the modeling of transported FFCO2 can come from separately tracking emissions of completely combusted fuels (i.e., as $\mathrm{CO}_{2}$ ) and those of only partially oxidized fuels (e.g., CO). Currently, most models simulating atmospheric $\mathrm{CO}_{2}$ transport assume $100 \%$ conversion from fuel to $\mathrm{CO}_{2}$. However, about $4 \%$ of all fossil fuel combusted is emitted as $\mathrm{CO}$ (which is later oxidized to $\mathrm{CO}_{2}$ ). The lifetime of $\mathrm{CO}$ in the atmosphere is on the order of months, but depends strongly on season and latitude. Thus, a small fraction of fuel combusted in North America, for example, will only appear as $\mathrm{CO}_{2}$ some months later in a diffuse pattern in a broad latitude range. Two studies (Folberth et al., 2005; Suntharalingam et al., 2005) quantified this effect and found a modest reduction of the systematic trend of $\mathrm{CO}_{2}$ concentration between Northern and Southern Hemispheres. This has the impact of reducing the Northern Hemisphere net sink and increasing the tropical $\mathrm{CO}_{2}$ net source. While these adjustments are within the uncertainty of existing inverse $\mathrm{CO}_{2}$ flux estimations, they represent biases that could be corrected in future studies.

Finally, an emerging method of directly tracking FFCO2 emissions is to use the radiocarbon content $\left(\Delta^{14} \mathrm{C}\right)$ of atmospheric $\mathrm{CO}_{2}$. There is no ${ }^{14} \mathrm{C}$ in fossil fuels because they are very old relative to the half-life of ${ }^{14} \mathrm{C}(\sim 5700$ years). Thus, atmospheric depletions in ${ }^{14} \mathrm{C}$ corresponding with increases in $\mathrm{CO}_{2}$ indicate recent fossil fuel additions. Measurements of ${ }^{14} \mathrm{CO}_{2}$ tend to be expensive and labor intensive, but small sets of observations have been used to partition total $\mathrm{CO}_{2}$ into fossil and terrestrial biological components (e.g., Miller et al., 2012; Graven et al., 2009; Turnbull et al., 2006) and directly estimate fossil fuel emissions (Turnbull et al., 2011; Levin et al., 2003). The latter two studies both showed good agreement with local-scale fossil fuel inventories. A related approach is to use ${ }^{14} \mathrm{CO}_{2}$ to "calibrate" other anthropogenic tracers like $\mathrm{CO}$ (which have more complicated budgets) to enable more cheaply and easily measured FFCO2 proxies (e.g., Turnbull et al., 2011; Vogel et al., 2010). While there are other sources and sinks that can impact interpretation of atmospheric ${ }^{14} \mathrm{CO}_{2}$ like heterotrophic respiration of the biosphere (Randerson et al., 2002) and emissions from nuclear power stations (Graven and Gruber, 2011), these fluxes are small relative to the fossil signal and can be quantified, making ${ }^{14} \mathrm{CO}_{2}$ a good tracer of $\mathrm{FFCO} 2$.

\section{Uncertainties}

Uncertainties associated with the FFCO2 emission data discussed in this synthesis fall into two broad categories: (1) those associated with the magnitude of the FFCO2 flux estimates themselves, and (2) those associated with the distribution of those emissions within an area or a volume. These distributions are described with two-dimensional maps (Sect. 6.2), three-dimensional maps (Sect. 6.3), and transport models (Sect. 7).

As noted in section 6.2, there are no independent physical measurements of FFCO2 emissions at the spatial and temporal scales relevant to the topics of this manuscript. However, that is not to say there are no constraints on the FFCO2 emission estimates presented in this manuscript. While it is true that the statistical energy data underlying the five global FFCO2 emissions inventories (Table 1) are generally selfreported data, there are varying degrees of oversight on these reported values. This oversight comes from: (1) governmental reporting (often in a taxation or regulatory environment); (2) from business reporting (often in terms of a production, refining, or transportation environment); and (3) from scientific reporting (e.g., the four lines of evidence presented in section 1 regarding the "physical environment side"). In addition, the long-term consistency and clear evidence in the energy data time series of known political (e.g., war) and economic (e.g., major recessions and energy crises) impacts lend confidence in these energy data sources.

\subsection{Uncertainties associated with national and global FFCO2 fluxes}

Marland and Rotty (1984) estimated uncertainties associated with the global FFCO2 estimate on the order of 6 to $10 \%$ 
(90\% confidence interval). Their approach was to examine the individual terms (e.g., quantity of fuel, carbon content of fuel, and fraction oxidized) used in the basic equation to calculate FFCO2 emissions from the energy statistics. Andres (unpublished data) has produced an independent estimate of $3.3 \%$ (95\% confidence interval). His analysis was based upon quantifying the qualitative national error classes of Andres et al (1996). The uncertainty associated with the global FFCO2 curve (e.g., Fig. 3a) is increasing with time, reflecting the growing magnitude of emissions from countries whose FFCO2 emissions are less certain (Fig. 7a).

Estimates of the $95 \%$ confidence interval uncertainties on FFCO2 emissions from individual nations range from 3-5\% for the US (USEPA, 2006) to 15-20\% for China (Gregg et al., 2008) to estimates of $50 \%$ or more for countries with poorly developed or poorly maintained statistical infrastructures (Andres and Marland, unpublished data; Marland et al., 1999). At the global scale, the magnitudes of emissions from countries with large uncertainties are generally small relative to the global total, so their cumulative effect is small on our understanding of the global total. The uncertainty on global FFCO2 emissions is dominated by the magnitude of FFCO2 emissions from the largest national emitters and the uncertainty associated with those emitters (Marland et al., 1999). Marland et al. (2009) discuss several lines of evidence for evaluating the uncertainty of emissions estimates, including the extent to which estimates are revised over time subsequent to their initial publication, and Pacala et al. (2010) discuss uncertainty at length in the context of possibilities for independent verification of nationally reported emission inventories.

Improvements to the FFCO2 emissions inventories and reduction of uncertainties associated with those inventories could be achieved by increased collection of statistics by the national statistical offices, agencies and/or energy ministries. There is room for improvements of all aspects of the data including the quantity of fuel consumed, the calorific and carbon content of that fuel consumed, and its combustion efficiency (e.g., Quick, 2010). A further challenge is collecting these statistics at the national scale, especially their time varying components as primary fuel suppliers change. Pacala et al. (2010) argue strongly for international support of data collection and management in countries with weak statistical infrastructures. Improvements can be realized in all nations. For example, Ackerman and Sundquist (2008) compared emissions estimates from US power plants as compiled by two different US government entities. While overall agreement was $2-3 \%$, they found differences as high as $25 \%$ at individual plants.

\subsection{Uncertainties associated with the FFCO2 distributions}

The uncertainty associated with two-dimensional (i.e., spatial) distributions of the $\mathrm{FFCO} 2$ inventories are related to three aspects: (1) the FFCO2 inventories; (2) the distribution proxy and/or models; and (3) the baseline (i.e., nationalscale) map itself. Each of these will be discussed in turn.

Uncertainty with the FFCO2 inventories themselves are discussed in Sect. 8.1. Local or regional inventories rely on surveys, census, and other data related to energy consumption or activities directly related to energy consumption, but data collection and management vary widely in quality around the world. Local knowledge of the energy system and fuels in use should result in improved data, but require infrastructure and continuity. As with all statistical problems that combine multiple data sources, these improvements require proper specification of the uncertainties on the inventories at different scales.

Uncertainty with the distribution proxy and/or models is dependent upon how well the proxy/model represent the portion of the FFCO2 inventory to be distributed and can be grouped into three uncertainty categories: (1) space, (2) time, and (3) coverage. Spatial uncertainty refers to how well the proxy/model captures the surficial arrangement of FFCO2 emission sources. For example, as discussed in Sect. 6, population density can serve as a first order FFCO2 emissions distribution. However, population does not capture well large point sources, particularly in thinly populated areas (e.g., remote coal-fired power stations, steel plants, refineries, etc). Temporal uncertainty refers to how well the proxy/model captures annual, diurnal, or other temporal cycles of energy use. For example, a FFCO2 distribution based on a commonly used large point source database does not capture well newly constructed large point sources, decommissioned large point sources, and large point sources temporarily shut down for refurbishment or maintenance. Proxies/models may also be scale dependent (e.g., population density does not work as well at finer spatial and temporal scales). Coverage refers to how well the proxy/model captures the full range of FFCO2 emission sources. For example, a FFCO2 distribution based on specific processes only captures the processes specifically modeled (e.g., are within-country shipping and/or boating specifically modeled?). As discussed in Sect. 6, other distribution proxies have been employed to improve FFCO2 distributions. All presently used distributions of FFCO2 emissions suffer from at least one of these uncertainty sources (i.e., space, time, and coverage). The full evaluation of distribution proxies is hampered by the lack of physical, independent measurements of FFCO2 emissions at relevant spatial and temporal scales.

Uncertainty with the baseline map itself is dependent upon: (1) the relative match of the map units with the FFCO2 inventory units in terms of spatial (and temporal) scales, and (2) the treatment of borders. The data required for FFCO2 emission inventories are usually collected by political units (e.g., nation, state/province, city) or business entities. Baseline maps are usually compiled in vector format (e.g., lines which map political borders) or raster format (e.g., rectangular grids which are used to approximate political 
borders). Uncertainty arises when the FFCO2 inventory does not match well the baseline map borders (in areal extent). Uncertainty also arises when there is incomplete or overlapping coverage between the FFCO2 inventory and the baseline map. Finally, uncertainty arises when a fixed baseline map is used to distribute a FFCO2 inventory that has multiple time slices. If the two do not match in time, then uncertainty arises as borders relocate (e.g., the disaggregation of the Former Soviet Union into 15 nations, the unification of Vietnam, the physical/political movement of the border between France and Germany as a result of military conflicts).

Uncertainty may also result if there is disagreement between the resolution of the two-dimensional FFCO2 distribution and its intended use. For example in the spatial realm, if the FFCO2 distribution has a spatial resolution of $1^{\circ}$ latitude by $1^{\circ}$ longitude and it is to be used as an input to an atmospheric transport model running at a spatial resolution of $2.8^{\circ}$ latitude by $2.8^{\circ}$ longitude (i.e., the T42 resolution), then decisions need to be made about how to aggregate and reformat the FFCO2 inventory to fit the transport model grid. To illustrate the disaggregation issue, an example from temporal resolution is used. If the FFCO2 inventory is annual in time step and the atmospheric transport model is running with a 20 minute time step (e.g., the NCAR CCM2, Hack et al., 1993), then decisions need to be made on how to disaggregate and reformat the FFCO2 inventory to fit the transport model time step. One approach is given in Fig. $6 \mathrm{~b}$ where a flux-conserving spline interpolation is demonstrated.

Uncertainty may also result from the treatment of borders. For example, if a $1^{\circ}$ latitude by $1^{\circ}$ longitude grid cell contains the land area of two or more countries, how should that grid cell be apportioned in the baseline map? CDIAC has taken the approach that the country with the dominant land mass in the cell occupies the entire cell. EDGAR has taken the approach that the cell is divided proportionally by land mass. This is an example of two different solutions that lead to different FFCO2 distributions. This border issue is further complicated if the border separates land from water (e.g., a lake or ocean). Again, a spatial dominance or proportional allocation decision can be made. This instance is unlike the two countries sharing a grid cell because most portions of FFCO2 inventories concern themselves with emissions from land. Thus, the placement of water is of importance. In a total FFCO2-conserving distribution scheme, the apportionment or non-apportionment of FFCO2 to a specific grid cell (either due to political unit sharing or water body sharing) affects the apportionment of FFCO2 to the other grid cells.

Usually, uncertainty is not reported on FFCO2 distribution maps. In this context, comparing two distributions can give useful insights, even though underlying data are usually not fully independent. Comparison between EDGAR and CDIAC inventories for country scale emissions showed that the largest percentage emission differences were for some developing countries (Marland et al., 1999), but the largest absolute differences were for developed countries with the largest emission magnitudes. The two estimates for the US differed by only $0.9 \%$, but in absolute terms this difference was more than the total FFCO2 emissions from 147 of the 195 countries considered.

In another data comparison exercise, four FFCO2 distributions [CDIAC, Marland et al. (2006); the Greenhouse Gas and Air Pollution Interactions and Synergies (GAINS) from the International Institute for Applied Systems Analysis (IIASA), Höglund-Isaksson \& Mechler (2005), Klaassen et al. (2005), Lükewille et al. (2006); the UNFCCC national communications, UNFCCC (2004); and EDGARv3.2 FT2000 data set, Olivier et al. (2005a), Van Aardenne et al. (2005)] for the years 1990 and 2000 were compared by Ciais et al. (2010) for European countries. Gross comparison of country totals showed a range on the order of $19 \%$ around their mean. When FFCO2 inventories were compared on an equal basis (e.g., to remove bunker fuels, cement production, hydrocarbon oxidation, and non-energy use products), these differences reduced to $7 \%$.

While the above two attempts to compare emission inventories examined national totals for a given year, distribution comparisons can also be made at finer spatial and temporal scales. Ciais et al. (2010) compared two different emission maps over Europe. An increasing difference between the two products was obtained down to finer spatial and temporal scales, with root mean square error between the maps increasing to $40 \mathrm{~g} \mathrm{C} \mathrm{m}^{-2} \mathrm{~d}^{-1}$ at $50 \mathrm{~km}$ resolution, and being higher in winter than in summer.

Rayner et al. (2010) showed that uncertainty in their emissions maps at 0.25 degrees arose largely from uncertainty in their spatial proxy (nighttime lights) and was higher at low emissions where the measured night light intensity approached the detection limit. Importantly for their use in atmospheric inversions, uncertainties in national emissions imposed correlated uncertainties among pixels in the same country.

As a final illustration of comparing two data sets, annual totals of the EDGAR version 4 FFCO2 distribution are compared with the Institute of Energy Economics and the Rational Use of Energy (IER) FFCO2 distribution (Pregger et al., 2007 ) for the year 2003. Figure $7 \mathrm{~b}$ shows results for various spatial resolutions. The highest (i.e., 1/12 degree) spatial resolution shows the most disagreement between the two estimates. At this spatial scale, the relative differences are largest for the largest FFCO2 fluxes (right side of the whisker plots). For larger FFCO2 fluxes, the relative differences decrease as spatial resolution decreases; this may reflect location errors of large point sources which become insignificant with decreasing spatial resolution. For smaller FFCO2 fluxes, the relative differences are somewhat insensitive to spatial resolution.

Finally, as the community asks for and creates more FFCO2 emission inventories with detailed spatial and temporal resolutions, the community must be vigilant that the resulting data and distributions show true properties of the 
FFCO2 data and not of the distribution proxies. For example, in a total FFCO2-conserving distribution scheme where FFCO2 apportionment in one cell affects FFCO2 apportionment in other cells, errors are not independent. Uncertainty can only be fully understood systemically. In addition, because the distribution of emissions spatially tends to be heavily skewed (some regions or grid cells have FFCO2 emissions many orders of magnitude higher than others), the error percentage tends to increase for areas where the absolute emissions are higher; errors are heteroscedastic (Gregg and Andres, 2008). This is in contrast to error estimates between national inventories (e.g., Marland et al., 1999) where the countries with the largest absolute emissions tended to have lower error rates.

\subsection{Uncertainties associated with FFCO2 in transport models}

There are at least two additional primary uncertainties associated with FFCO2 and transport models: (1) depth of the planetary boundary layer, and (2) large-scale transport. Both of these have impacts in terms of comparing model output with physical measurements of $\mathrm{CO}_{2}$ in the atmosphere.

Models convert FFCO2 inventory flux estimates (in units of mass per time) into concentration estimates (in units of molecules per volume, e.g., ppm, or mole of $\mathrm{FFCO} 2$ per mole of air, e.g., mole fraction). The inventory and distribution methodology supply the areal extent of the emission volume. The model supplies the vertical dimension of the emission volume. A change in vertical dimension of the input volume changes the resulting FFCO2 concentration. Since FFCO2 inventory estimates are placed into the lowest model atmospheric level (vertical distribution of FFCO2 emissions from high smokestacks or aircraft has not been incorporated in most models), the timing and magnitude of planetary boundary layer mixing are critical. For example, a too shallow model boundary layer will simulate unrealistically high $\mathrm{CO}_{2}$ concentrations near the Earth's surface.

Transport, through advection and diffusion, then moves both the FFCO2 and other $\mathrm{CO}_{2}$ throughout the atmosphere. Errors in transport change the downwind concentration of FFCO2 and total $\mathrm{CO}_{2}$. This is problematic as atmospheric sampling of $\mathrm{CO}_{2}$ at various locations and altitudes is then used as a primary means of validating transport model performance. Transport errors are difficult to diagnose, and in many studies atmospheric transport is assumed to be perfectly known. For inversion models of the carbon cycle, the result of the inevitable errors in transport is undiagnosed errors in the retrieved oceanic and biospheric fluxes.

\section{Conclusions}

The primary conclusion of this synthesis is that FFCO2 emissions to the atmosphere continue to increase with time (pri- marily due to electricity generation and road transportation). Since anthropogenic emissions of $\mathrm{CO}_{2}$ are one of the main drivers of climate change (IPCC, 2007), this increase in FFCO2 emissions is of concern because of the potential negative ramifications on the environment and human society. While FFCO2 emissions reduction is not a universal concern at present, the long atmospheric lifetime of FFCO2 (and $\mathrm{CO}_{2}$, in general) means that current $\mathrm{FFCO} 2$ emissions have a long-term implication. This implication includes if negative ramifications are realized from climate change and if society wants to reduce such ramifications in the future, significant fractions of FFCO2 emissions released today will remain in the atmosphere for centuries (Hansen et al., 2007).

The secondary conclusion of this synthesis is that much is known about FFCO2 emissions. Yet, much is still to be understood about these emissions - especially at the temporal and spatial scales of countries and smaller political units where combustion (and mitigation) actions are taken. There are increasing demands for higher time/space resolution of FFCO2 emission estimates and quantified uncertainties from both those interested directly in verification and mitigation activities and scientifically from carbon cycle researchers.

There are synergies to be gained through additional knowledge about FFCO2 emissions, in particular with how those emissions impact the environment and society. This expands upon the ideas presented by Butler et al. (2008) who called for more detailed knowledge about where $\mathrm{FFCO} 2$ emissions were occurring to better understand economic controls on FFCO2 emissions. This expansion builds upon a better understanding of present economic controls, by providing more economic opportunity. For example, the additional studies needed to improve burner efficiencies inform engineering design to bring better burners to market would also improve FFCO2 calculations. A second example is that better data on population distributions in space and time would support better emergency response preparations, better infrastructure planning, more targeted advertising, and optimized store locations would also allow more accurate $\mathrm{FFCO} 2$ distributions to be constructed. A third example is that more and improved (in space and time) satellite measurements would allow a better understanding of the topology of our energy, transportation, and other economic infrastructures, and the vulnerability of those infrastructures to various threats would also allow more accurate FFCO2 distributions to be constructed. A final example is that improved climate and weather models would allow better short (e.g., days), medium (e.g., weeks), and longer term (e.g., years) weather forecasts. These are important not only in the agricultural sector (e.g., do I pay for irrigation water today or wait for the free rain tomorrow?), but also in other economic sectors (e.g., for a new Chinese city to be built, how much reservoir capacity needs to be built to supply the domestic and industrial water needs?). Improved climate and weather models also have the synergy of improving our understanding of the effects of increased FFCO2 on the environment. 
Acknowledgements. The work of RJA, TAB, and DE was sponsored by US Department of Energy, Office of Science, Biological and Environmental Research (BER) programs and performed at Oak Ridge National Laboratory (ORNL). ORNL is managed by UT-Battelle, LLC, for the US Department of Energy under contract DE-AC05-00OR22725. The submitted manuscript has been co-authored by a contractor of the US Government under contract DE-AC05-00OR22725. Accordingly, the US Government retains a nonexclusive, royalty-free license to publish or reproduce the published form of this contribution, or allow others to do so, for US Government purposes. JGJO acknowledges the European Union's Joint Research Centre (EU-JRC) for the maintenance of the EDGAR system and for making the data of EDGAR 4.2 publicly available. PR is in receipt of an Australian Research Council Professorial Fellowship (DP1096309). KT's copyright for this publication is held by the International Energy Agency, an autonomous agency within the framework of the Organisation for Economic Co-operation and Development.

Edited by: C. Sabine

\section{References}

Ackerman, K. V. and Sundquist, E. T.: Comparison of two US power-plant carbon dioxide emissions data sets, Environ. Sci. Technol., 42, 5688-5693, doi:10.1021/es800221q, 2008.

Allen, M. R., Frame, D. J., Huntingford, C., Jones, C. D., Lowe, J. A., Meinshausen, M., and Meinshausen, N.: Warming caused by cumulative carbon emissions: Towards the trillionth tonne, Nature, 458, 1163-1166, doi:10.1038/nature08019, 2009.

Andres, R. J., Marland, G., Fung, I., and Matthews, E.: A one degree by one degree distribution of carbon dioxide emissions from fossil fuel consumption and cement manufacture, 1950-1990, Global Biogeochem. Cy., 10, 419-429, doi:10.1029/96GB01523, 1996.

Andres, R. J., Fielding, D. J., Marland, G., Boden, T. A., Kumar, N., and Kearney, A. T.: Carbon dioxide emissions from fossilfuel use, 1751-1950, Tellus, 51, 759-765, doi:10.1034/j.16000889.1999.t01-3-00002.x, 1999.

Andres, R. J., Gregg, J. S., Losey, L., Marland, G., and Boden, T. A.: Monthly, global emissions of carbon dioxide from fossil fuel consumption, Tellus B, 63, 309-327, doi:10.1111/j.16000889.2011.00530.x, 2011.

Apergis, N. and Payne, J. E.: Energy consumption and economic growth in Central America: Evidence from a panel cointegration and error correction model, Energ. Econ., 31, 211-216, doi:10.1016/j.eneco.2008.09.002, 2009.

Belke, A., Dobnik, F., and Dreger, C.: Energy consumption and economic growth: New insights into the cointegration relationship, Energ. Econ., 33, 782-789, doi:10.1016/j.eneco.2011.02.005, 2011

Bernstein, L. and Roy, J.: Industry, in Climate Change 2007: Mitigation of Climate Change, edited by: Metz, B., Davidson, O. R., Bosch, P. R., Dave, R., and Meyer, L. A., 447-496, Cambridge University Press, Cambridge, U. K., 2007.

Blasing, T. J., Broniak, C., and Marland, G.: State-by-state carbon dioxide emissions from fossil-fuel use in the United States 1960
2000, Mitigation and Adaptation Strategies for Global Change, 10, 659-674, doi:10.1007/s11027-005-6471-9, 2005a.

Blasing, T. J., Broniak, C., and Marland, G.: The annual cycle of fossil-fuel carbon dioxide emissions in the United States, Tellus B, 57, 107-115, doi:10.1111/j.1600-0889.2005.00136.x, 2005 b.

Boden, T. A., Marland, G., and Andres, R. J.: Global, regional, and national fossil-fuel $\mathrm{CO}_{2}$ emissions, Carbon Dioxide Information Analysis Center, Oak Ridge National Laboratory, US Department of Energy, Oak Ridge, TN, doi:10.3334/CDIAC/00001_V2010, 2010.

Boucher, O., Friedlingstein, P., Collins B., and Shine, K. P.: The indirect global warming potential and global temperature chnage potential due to methane oxidation, Environ. Res Lett., 4, 044007 doi:10.1088/1748-9326/4/4/044007.

Brenkert, A. L.: Carbon dioxide emission estimates from fossilfuel burning, hydraulic cement production, and gas flaring for 1995 on a one degree grid cell basis, Carbon Dioxide Information Analysis Center, Oak Ridge National Laboratory, US Department of Energy, Oak Ridge, TN, http://cdiac.ornl.gov/ndps/ ndp058a.html, 1998.

Butler, T. M., Lawrence, M. G., Gurjar, B. R., van Aardenne, J., Schultz, M., and Lelieveld, J.: The representation of emissions from megacities in global emission inventories, Atmos. Environ., 42, 703-719, doi:10.1016/j.atmosenv.2007.09.060, 2008.

Ciais, P., Tans, P. P., White, J. W. C., Trolier, M., Francey, R. J., Berry, J. A., Random, D. R., Sellers, P. J., Collatz, J. G., and Schimel, D. S.: Partitioning of ocean and land uptake of $\mathrm{CO}_{2}$ as inferred by $\delta^{13} \mathrm{C}$ measurements from the NOAA Climate Monitoring and Diagnostics Laboratory global air sampling network, J. Geophys. Res., 100, 5051-5070, doi:10.1029/94JD02847, 1995.

Ciais, P, Paris, J. D., Marland, G., Peylin, P., Piao, S. L., Levin, I., Pregger, T., Scholz, Y., Friedrich, R., Rivier, L., Houweling, S., and Schulze, E. D.: The European carbon balance. Part 1: Fossil fuel emissions, Global Change Biol., 16, 1395-1408, doi:10.1111/j.1365-2486.2009.02098.x, 2010.

Corbin, K. D., Denning, A. S., and Gurney, K. R.: The space and time impacts on US regional atmospheric $\mathrm{CO}_{2}$ concentrations from a high resolution fossil fuel $\mathrm{CO} 2$ emissions inventory, Tellus B, 62, 506-511, doi:10.1111/j.1600-0889.2010.00480.x, 2010.

Davis, S. J. and Caldeira, K.: Consumption-based accounting of $\mathrm{CO}_{2}$ emissions, P. Natl. Acad. Sci. USA, 107, 5687-5692, doi:10.1073/pnas.0906974107, 2010.

Davis, S. J., Peters, G. P., and Caldeira, K.: The supply chain of $\mathrm{CO}_{2}$ emissions, P. Natl. Acad. Sci. USA, 108, 18554-18559, doi:10.1073/pnas.1107409108, 2011.

Denman, K. L., Brasseur, G., Chidthaisong, A., Ciais, P., Cox, P. M., Dickinson, R. E., Hauglustaine, D., Heinze, C., Holland, E., Jacob, D., Lohmann, U., Ramachandran, S., da Silva Dias, P. L., Wofsy, S. C., and Zhang, X.: Couplings between changes in the climate system and biogeochemistry, in Climate Change 2007: The Physical Science Basis, edited by: Solomon, S., Qin, D., Manning, M., Chen, Z., Marquis, M., Averyt, K. B., Tignor, M., and Miller, H. L., 516, 517, Cambridge University Press, Cambridge, U. K., 2007.

Doll, C. N. H., Muller, J.-P., and Elvidge, C. D.: Night-time imagery as a tool for global mapping of socioeconomic parameters and greenhouse gas emissions, Ambio, 29, 157-162, 
doi:10.1579/0044-7447-29.3.157, 2000.

Elvidge, C. D., Baugh, K. E., Kihn, E. A., Kroehl, H. W., and Davis, E. R.: Mapping city lights with nighttime data from the DMSP operational linescan system, Photogramm. Eng. Rem. S., 63, 727-734, 1997.

Elvidge, C. D., Baugh, K. E., Dietz, J. B., Bland, T., Sutton, P. C., and Kroehl, H. W.: Radiance calibration of DMSP-OLS lowlight imaging data of human settlements - a new device for portraying the Earth's surface entire, Remote Sens. Environ., 68, 7788, 1999.

Elvidge, C. D., Ziskin, D., Baugh, K. E., Tuttle, B. J., Ghosh, T., Pack, D. W., Erwin, E. H., and Zhiskin, M.: A fifteen year record of global natural gas flaring derived from satellite data, Energies, 2, 595-622, doi:10.3390/en20300595, 2009.

Energy Information Administration (EIA): International energy statistics, available at: http://www.eia.gov/cfapps/ipdbproject/ IEDIndex3.cfm, 2011a.

EIA: Carbon intensity using market exchange rates (metric tons of carbon dioxide per thousand year 2005 US dollars), available at: http://www.eia.gov/cfapps/ipdbproject/IEDIndex3.cfm? tid=91\&pid=46\&aid=31, $2011 \mathrm{~b}$.

Enting, I. G. Trudinger C. M., and Francey R. J.: A synthesis inversion of the concentration and $\delta^{13} \mathrm{C}$ of atmospheric $\mathrm{CO}_{2}$, Tellus B, 47, 35-52, 1995.

Enting, I. G., Rayner, P. J., and Ciais, P.: RECCAP uncertainty, Biogeosciences, accepted, 2012.

Erickson III, D. J., Mills, R. T., Gregg, J., Blasing, T. J., Hoffman, F. M.., Andres, R. J., Devries, M., Zhu, Z., and Kawa, S. R.: An estimate of monthly global emissions of anthropogenic $\mathrm{CO}_{2}$ : Impact on the seasonal cycle of atmospheric $\mathrm{CO}_{2}$, J. Geophys. Res., 113, G01023, doi:10.1029/2007JG000435, 2008.

European Commission Joint Research Centre/PBL Netherlands Environmental Assessment Agency (EC-JRC/PBL): Emission Database for Global Atmospheric Research, EDGAR version 4.2, http://edgar.jrc.ec.europa.eu, 2011.

Folberth, G., Hauglustaine, D. A., Ciais, P., and Lathiere, J.: On the role of atmospheric chemistry in the global $\mathrm{CO}_{2}$ budget, Geophys. Res. Lett., 32, L08801, doi:10.1029/2004GL021812, 2005.

Forster, P., Ramaswamy, V., Artaxo, P., Berntsen, T., Betts, R., Fahey, D. W., Haywood, J., Lean, J., Lowe, D. C., Myhre, G., Nganga, J., Prinn, R., Raga, G., Schulz, M., and Van Dorland, R.: Changes in atmospheric constituents and in radiative forcing, in: Climate Change 2007: The Physical Science Basis, edited by: Solomon, S., Qin, D., Manning, M., Chen, Z., Marquis, M., Averyt, K. B., Tignor, M., and Miller, H. L., 138, Cambridge University Press, Cambridge, U. K., 2007.

Freitas, S. R., Longo, K. M., and Andreae, M. O.: Impact of including the plume rise of vegetation fires in numerical simulations of associated atmospheric pollutants, Geophys. Res. Lett., 33, L17808, doi:10.1029/2006GL026608, 2006.

Friedlingstein, P., Houghton, R. A., Marland, G., Hackler, J. L., Boden, T. A., Conway, T. J., Canadell, J. G., Raupach, M. R., Ciais, P., and Le Quéré, C.: Update on $\mathrm{CO}_{2}$ emissions, Nat. Geosci., 3, 811-812, doi:10.1038/ngeo1022, 2010.

Ghosh, T., Elvidge, C. D., Sutton, P. C., Baugh, K. E., Ziskin, D., and Tuttle, B. T.: Creating a global grid of distributed fossil fuel $\mathrm{CO}_{2}$ emissions from nighttime satellite imagery, Energies, 3, 1895-1913, doi:10.3390/en3121895, 2010.
Graven, H. D. and Gruber, N.: Continental-scale enrichment of atmospheric ${ }^{14} \mathrm{CO}_{2}$ from the nuclear power industry: potential impact on the estimation of fossil fuel-derived $\mathrm{CO}_{2}$, Atmos. Chem. Phys. Discuss., 11, 14583-14605, doi:10.5194/acpd-11-145832011, 2011.

Graven, H. D., Stephens, B. B., Guilderson, T. P., Campos, T. L., Schimel, D. S., Campbell, J. E., and Keeling R. F.: Vertical profiles of biospheric and fossil fuel-derived $\mathrm{CO}_{2}$ and fossil fuel $\mathrm{CO}_{2}$ : $\mathrm{CO}$ ratios from airborne measurements of $\Delta^{14} \mathrm{C}$, $\mathrm{CO}_{2}$ and $\mathrm{CO}$ above Colorado, USA, Tellus B, 61, 536-546, doi:10.1111/j.1600-0889.2009.00421.x, 2009.

Gregg, J. S. and Andres, R. J.: A method for estimating the temporal and spatial patterns of carbon dioxide emissions from national fossil-fuel consumption, Tellus B, 60, 1-10, doi:10.1111/j.16000889.2007.00319.x, 2008.

Gregg, J. S., Andres, R. J., and Marland, G.: China: Emissions pattern of the world leader in $\mathrm{CO}_{2}$ emissions from fossil fuel consumption and cement production, Geophys. Res. Lett., 35, L08806, doi:10.1029/2007GL032887, 2008.

Gregg, J. S., Losey, L. M., Andres, R. J., Blasing, T. J., and Marland, G.: The temporal and spatial distribution of carbon dioxide emissions from fossil-fuel use in North America, J. Appl. Meteorol. Clim., 48, 2528-2542, doi:10.1175/2009JAMC2115.1, 2009.

Gurney, K. R., Rachel, L. M., Denning, A. S., Rayner, P. J., Baker, D., Bousquet, P., Bruhwiler, L., Chen, Y.-H., Ciais, P., Fan, S., Fung, I. Y., Gloor, M., Heimann, M., Higuchi, K., John, J., Maki, T., Maksyutov, S., Masarie, K., Peylin, P., Prather, M., Pak, B. C., Randerson, J., Sarmiento, J., Taguchi, S., Takahashi, T., and Yuen, C.-W.: Towards robust regional estimates of $\mathrm{CO}_{2}$ sources and sinks using atmospheric transport models, Nature, 415, 626630, doi:10.1038/415626a, 2002.

Gurney, K. R., Mendoza, D. L., Zhou, Y., Fischer, M. L., Miller, C. C., Geethakumar, S., and de la Rue du Can, S.: High resolution fossil fuel combustion $\mathrm{CO}_{2}$ emission fluxes for the United States, Environ. Sci. Technol., 43, 5535-5541, doi:10.1021/es900806c, 2009.

Hack, J. J., Boville, B. A., Briegleb, B. P., Kiehl, J. T., Rasch, P. J., and Williamson, D. L.: Description of the NCAR Community Climate Model (CCM2), NCAR Tech. Note, NCAR/TN382+STR, National Center for Atmospheric Research, Boulder, CO, 108 pp., 1993.

Hansen, J., Sato, M., Ruedy, R., Kharecha, P., Lacis, A., Miller, R., Nazarenko, L., Lo, K., Schmidt, G. A., Russell, G., Aleinov, I., Bauer, S., Baum, E., Cairns, B., Canuto, V., Chandler, M., Cheng, Y., Cohen, A., Del Genio, A., Faluvegi, G., Fleming, E., Friend, A., Hall, T., Jackman, C., Jonas, J., Kelley, M., Kiang, N. Y., Koch, D., Labow, G., Lerner, J., Menon, S., Novakov, T., Oinas, V., Perlwitz, Ja., Perlwitz, Ju., Rind, D., Romanou, A., Schmunk, R., Shindell, D., Stone, P., Sun, S., Streets, D., Tausnev, N., Thresher, D., Unger, N., Yao, M., and Zhang, S.: Dangerous human-made interference with climate: a GISS modelE study, Atmos. Chem. Phys., 7, 2287-2312, doi:10.5194/acp-72287-2007, 2007.

Höglund-Isaksson, L. and Mechler, R.: The GAINS Model for Greenhouse Gases - Version 1.0: Methane $\left(\mathrm{CH}_{4}\right)$, IIASA Interim Report IR-05-54, h-ttp://www.iiasa.ac.at/rains/reports/ IR54-GAINS-CH4.pdf, 2005.

Houghton, R. A., van der Werf, G. R., DeFries, R. S., Hansen, M. C., House, J. I., Le Quéré, C., Pongratz, J., and Ramankutty 
N.: Chapter G2 Carbon emissions from land use and land-cover change, Biogeosciences, in press, 2012.

Hungerschoefer, K., Breon, F.-M., Peylin, P., Chevallier, F., Rayner, P., Klonecki, A., Houweling, S., and Marshall, J.: Evaluation of various observing systems for the global monitoring of $\mathrm{CO}_{2}$ surface fluxes, Atmos. Chem. Phys., 10, 10503-10520, doi:10.5194/acp-10-10503-2010, 2010.

Imhoff, M. and Elvidge, C.: Earth's city lights, available at: http: //visibleearth.nasa.gov/view_rec.php?id=1438, 2000.

Intergovernmental Panel on Climate Change (IPCC): Revised 1996 IPCC Guidelines for National Greenhouse Gas Inventories, IPCC WGI Technical Support Unit, Bracknell, U. K., 1996.

IPCC: Guidelines for National Greenhouse Gas Inventories, v. 11, IPCC WGI Technical Support Unit, Bracknell, U. K., 2006.

IPCC: Climate Change 2007: The Physical Science Basis, edited by: Solomon, S., Qin, D., Manning, M., Chen, Z., Marquis, M., Averyt, K. B., Tignor, M., and Miller, H. L., Cambridge University Press, Cambridge, U. K., 2007.

International Energy Agency (OECD/IEA): $\mathrm{CO}_{2}$ emissions from fuel combustion, 2010 edition, OECD/IEA, Paris, 2010.

Kashiwagi, T.: Industry, in Climate Change 1995: Impacts, Adaptations, and Mitigation of Climate Change: Scientific-Technical Analysis, edited by: Watson, R. T., Zinoyowera, M. C., and Moss, R. H., 649-677, Cambridge University Press, Cambridge, U. K., 1996.

Kawa, S. R., Erickson III, D. J., Pawson, S., and Zhu, Z.: Global $\mathrm{CO}_{2}$ transport simulations using meteorological data from the NASA data assimilation system, J. Geophys. Res., 109, D18312, doi:10.1029/2004JD004554, 2004.

Keeling, R. F., Najjar, R. P., Bender, M. L., and Tans, P. P.: What atmospheric oxygen measurements can tell us about the global carbon cycle, Global Biogeochem. Cy., 7, 37-67, doi:10.1029/92GB02733, 1993.

Klaassen, G., Berglund, C., and Wagner, F.: The GAINS Model for Greenhouse Gases - Version 1.0: Carbon Dioxide $\left(\mathrm{CO}_{2}\right)$, IIASA Interim Report IR-05-53, available at: http://www.iiasa. ac.at/rains/reports/IR53-GAINS-CO2.pdf, 2005.

Kyoto Protocol to the United Nations Framework Convention on Climate Change (KP): United Nations, New York, 21 pp., 1998.

Le Quéré, C., Raupach, M. R., Canadell, J. G., Marland, G., Bopp, L., Ciais, P., Conway, T. J., Doney, S. C., Feely, R. A., Foster, P., Friedlingstein, P., Gurney, K., Houghton, R. A., House, J. I., Huntingford, C., Levy, P. E., Lomas, M. R., Majkut, J., Metzl, N., Ometto, J. P., Peters, G. P., Prentice, I. C., Randerson, J. T., Running, S. W., Sarmiento, J. L., Schuster, U., Sitch, S., Takahashi, T., Viovy, N., van der Werf, G. R., and Woodward, F. I.: Trends in the sources and sinks of carbon dioxide, Nat. Geosci., 2, 831-836, doi:10.1038/ngeo689, 2009.

Levin, I., Kromer, B., Schmidt, M., and Sartorius, H.: A novel approach for independent budgeting of fossil fuel $\mathrm{CO}_{2}$ over Europe by ${ }^{14} \mathrm{CO}_{2}$ observations, Geophys. Res. Lett., 30, 2194, doi:10.1029/2003GL018477, 2003.

Levin, I., Naegler, T., Kromer, B., Diehl, M., Francey, R. J., GomezPelaez, A. J., Steele, L. P., Wagenbach, D., Weller, R., and Worthy, D. E.: Observations and modelling of the global distribution and long-term trend of atmospheric ${ }^{14} \mathrm{CO}_{2}$, Tellus B, 62, 26-26, doi:10.1111/j.1600-0889.2009.00446.x, 2010.

Levine, M. and Ürge-Vorsatz, D.: Residential and commercial buildings, in Climate Change 2007: Mitigation of Climate
Change, edited by: Metz, B., Davidson, O. R., Bosch, P. R., Dave, R., and Meyer, L.A., 388-446, Cambridge University Press, Cambridge, U. K., 2007.

Losey, L. M., Andres, R. J., and Marland, G.: Monthly estimates of carbon dioxide emissions from fossil-fuel consumption in Brazil during the late 1990s and early 2000s, Area 38, 445-452, doi:10.1111/j.1475-4762.2006.00713.x, 2006.

Lükewille, A., Wilson, S., Pacyna, J., Steenhuisen, F., Panasiuk, D., and Manø, S.: Inventory of Baseline 1990 and 2003 Emissions, Final Report of the EVERGREEN EU funded project, 2006.

Macknick, J.: Energy and carbon dioxide emission data uncertainties, IR-09-032,International Institute for Applied Systems Analysis, Laxenburg, Austria, 55 pp., 2009.

Marland, G. and Rotty, R.: Carbon dioxide from fossil fuels: A procedure for estimation and results 1950-1982, Tellus B, 36, 232261, doi:10.1111/j.1600-0889.1984.tb00245.x, 1984.

Marland, G., Brenkert, A., and Olivier, J.: $\mathrm{CO}_{2}$ from fossil fuel burning: A comparison of ORNL and EDGAR estimates of national emissions, Environ. Sci. Policy, 2, 265-273, doi:10.1016/S1462-9011(99)00018-0, 1999.

Marland, G., Boden, T. A., and Andres, R. J.: Global, regional, and national fossil fuel $\mathrm{CO}_{2}$ emissions, in Trends: A Compendium of Data on Global Change, US Department of Energy, Carbon Dioxide Information Analysis Center, Oak Ridge National Laboratory, Oak Ridge, TN, 2006.

Marland, G., Andres, R. J., Blasing, T. J., Boden, T. A., Broniak, C. T., Gregg, J. S., Losey, L. M., and Treanton, K.: Energy, industry and waste management activities: An introduction to $\mathrm{CO}_{2}$ emissions from fossil fuels: A report by the US Climate Change Science Program and the Subcommittee on Global Change Research, in The First State of the Carbon Cycle Report (SOCCR): The North American Carbon Budget and Implications for the Global Carbon Cycle, edited by: King, A. W., Dilling, L., Zimmerman, G. P., Fairman, D. M., Houghton, R. A., Marland, G., Rose, A. Z., and Wilbanks, T. J., 57-64, Asheville, NC, 2007.

Marland, G., Hamal, K., and Jonas, M.: How uncertain are estimates of $\mathrm{CO}_{2}$ emissions?, J. Ind. Ecol., 13, 4-7, doi:10.1111/j.15309290.2009.00108.x, 2009.

Matthews, H. D., Gillett, N. P., Stott, P. A., and Zickfeld, K.: The proportionality of global warming to cumulative carbon emissions, Nature, 459, 829-833, doi:10.1038/nature08047, 2009.

Meinshausen, M., Meinshausen, N., Hare, W., Raper, S. C. B., Frieler, K., Knutti, R., Frame, D. J., and Allen, M. R.: Greenhouse-gas emission targets for limiting global warming to $2^{\circ} \mathrm{C}$, Nature, 458, 1158-1162, doi:10.1038/nature08017, 2009.

Michaelis, L.: Mitigation Options in the Transportation Sector, in Climate Change 1995: Impacts, Adaptations, and Mitigation of Climate Change: Scientific-Technical Analysis, edited by: Watson, R. T., Zinoyowera, M. C., and Moss, R. H., 679-712, Cambridge University Press, Cambridge, U. K., 1996.

Miller, J. B., Lehman, S. J., Montzka, S. A., Sweeney, C., Miller, B. R., Karion A., Wolak, C., Dlugokencky, E. J., Southon, J., Turnbull, J. C., and Tans, P. P.: Linking emissions of fossil fuel $\mathrm{CO}_{2}$ and other anthropogenic trace gases using atmospheric ${ }^{14} \mathrm{CO}_{2}$, J. Geophys. Res., 117, D08302, doi:10.1029/2011JD017048, 2012.

Nakicenovic, N., Alcamo, J., Davis, G., de Vries, B., Fenhann, J., Gaffin, S., Gregory, K., Grübler, A., Jung, T. Y., Kram, T., La Rovere, E. L., Michaelis, L., Mori, S., Morita, T., Pepper, W., Pitcher, H., Price, L., Riahi, K., Roehrl, A., Rogner, H.-H., 
Sankovski, A., Schlesinger, M., Shukla, P., Smith, S., Swart, R., van Rooijen, S., Victor, N., and Dadi, Z.: Emissions Scenarios, Cambridge University Press, Cambridge, U. K., 570 pp., 2000.

Nassar, R., Jones, D. B. A., Suntharalingam, P., Chen, J. M., Andres, R. J., Wecht, K. J., Yantosca, R. M., Kulawik, S. S., Bowman, K. W., Worden, J. R., Machida, T., and Matsueda, H.: Modeling global atmospheric $\mathrm{CO}_{2}$ with improved emission inventories and $\mathrm{CO}_{2}$ production from the oxidation of other carbon species, Geoscientific Model Development, 3, 689-716, doi:10.5194/gmd-3689-2010, 2010.

New York City (NYC): Greenhouse gas emission inventory, available at: http://www.nyc.gov/html/planyc2030/html/emissions/ emissions.shtml, 2010.

Oda, T. and Maksyutov, S.: A very high-resolution $(1 \mathrm{~km} \times 1 \mathrm{~km})$ global fossil fuel $\mathrm{CO}_{2}$ emission inventory derived using a point source database and satellite observations of nighttime lights, Atmos. Chem. Phys., 11, 543-556, doi:10.5194/acp-11-543-2011, 2011.

Olivier, J. G. J. and Berdowski, J. J. M.: Global emissions sources and sinks, in The Climate System, edited by: Berdowski, J., Guicherit, R., and Heij, B. J., 33-78, A.A. Balkema Publishers/Swets and Zeitlinger Publishers, Lisse, The Netherlands, 2001.

Olivier, J. G. J. and Janssens-Maenhout, G.: Part III: Greenhouse gas emissions, in: $\mathrm{CO}_{2}$ emissions from fuel combustion, 2011 Edition, III.1-III.49, International Energy Agency, Paris, 2011.

Olivier, J. G. J. and Peters, J. A. H. W.: No growth in total global $\mathrm{CO}_{2}$ emissions in 2009, PBL publication number 500212001, Netherlands Environmental Assessment Agency (PBL), Bilthoven, The Netherlands, 2010.

Olivier, J. G. J., Van Aardenne, J. A., Dentener, F., Ganzeveld, L., and Peters, J. A. H. W.: Recent trends in global greenhouse gas emissions: Regional trends and spatial distribution of key sources, in: Non- $\mathrm{CO}_{2}$ Greenhouse Gases (NCGG-4), coordinated by van Amstel, A., 325-330, Millpress Science Publishers, Rotterdam, 2005a.

Olivier, J. G. J., Van Aardenne, J. A., Dentener, F., Pagliari, V., Ganzeveld, L. N., and Peters, J. A. H. W.: Recent trends in global greenhouse gas emissions: regional trends 1970-2000 and spatial distribution of key sources in 2000, J. Integr. Environmental Sciences, 2, 81-99, doi:10.1080/15693430500400345, 2005b.

Olivier, J. G. J., Janssens-Maenhout, G., Peters, J. A. H. W., and Wilson, J.: Long-term trend in global $\mathrm{CO}_{2}$ emissions: 2011 report, PBL report number 500253004, JRC Technical Note number JRC65918, PBL, Bilthoven, The Netherlands, 2011.

Pacala, S. W., Breidenich, C., Brewer, P. G., Fung, I., Gunson, M. R., Heddle, G., Law, B., Marland, G., Paustian, K., Prather, M., Randerson, J. T., Tans, P., and Wofsy, S. C.: Verifying Greenhouse Gas Emissions, National Research Council, National Academies Press, Washington, D. C., 2010.

Peters, G. P., Davis, S. J., and Andrew, R. M.: A synthesis of carbon in international trade, Biogeosciences, accepted, 2012.

Peters, G. P., Marland, G., Quéré, C. L., Boden, T. A., Canadell, J. G., and Raupach, M. R.: Rapid growth in $\mathrm{CO}_{2}$ emissions after the 2008-2009 global financial crisis. Nat. Clim. Change 2, 2-4, 2011.

Peters, G. P., Minx, J. C., Weber, C. L., and Edenhofer, O.: Growth in emissions transfers via international trade from 1990 to 2008, P. Natl. Acad. Sci. USA, 108, 8903-8908, doi:10.1073/pnas.1006388108, 2011.

Peters, W., Jacobson, A. R., Sweeney, C., Andrews, A. E., Conway, T. J., Masarie, K., Miller, J. B., Bruhwiler, L. M. P., Pétron, G., Hirsch, A. I., Worthy , D. E. J., van der Werf, G. R., Randerson, J. T., Wennberg, P. O., Krol, M. C., and Tans, P. P.: An atmospheric perspective on North American carbon dioxide exchange: CarbonTracker, P. Natl. Acad. Sci. USA, 104, 1892518930, doi:10.1073/pnas.0708986104, 2007.

Pétron, G., Tans P., Frost, G., Chao, D., and Trainer., M.: Highresolution emissions of $\mathrm{CO}_{2}$ from power generation in the USA, J. Geophys. Res., 113, G04008, doi:10.1029/2007JG000602, 2008.

Pregger, T., Scholz, Y., and Friedrich, R.: Documentation of the Anthropogenic GHG Emission Data for Europe Provided in the Frame of CarboEurope GHG and CarboEurope IP, Final Report, University of Stuttgart, Institute of Energy Economics and the Rational Use of Energy, 37 pp., 2007.

Quick, J. C.: Carbon dioxide emission factors for US coal by origin and destination, Environ. Sci. Technol., 44, 2709-2714, doi:10.1021/es9027259, 2010.

Rafelski, L. E., Piper S. C., and Keeling, R. F.: Climate effects on atmospheric carbon dioxide over the last century, Tellus B, 61, 718-731, doi:10.1111/j.1600-0889.2009.00439.x, 2009.

Randerson, J. T., Enting, I. G., Schuur, E. A. G., Caldeira, K., and Fung, I. Y.: Seasonal and latitudinal variability of troposphere $\Delta^{14} \mathrm{CO}_{2}$ : Post bomb contributions from fossil fuels, oceans, the stratosphere, and the terrestrial biosphere, Global Biogeochem. Cy., 16, 1112, doi:10.1029/2002GB001876, 2002.

Raupach, M. R., Marland, G., Ciais, P., Le Quéré, C., Canadell, J. G., Klepper, G., and Field, C. B.: Global and regional drivers of accelerating $\mathrm{CO}_{2}$ emissions, P. Natl. Acad. Sci. USA, 104, 10288-10293, doi:10.1073/pnas.0700609104, 2007.

Raupach, M. R., Canadell, J. G., and Le Quéré, C.: Anthropogenic and biophysical contributions to increasing atmospheric $\mathrm{CO}_{2}$ growth rate and airborne fraction, Biogeosciences, 5, 1601-1613, doi:10.5194/bg-5-1601-2008, 2008.

Raupach, M. R., Canadell, J. G., Ciais, P., Friedlingstein, P., Rayner, P. J., and Trudinger, C. M.: The relationship between peak warming and cumulative $\mathrm{CO}_{2}$ emissions, and its use to quantify vulnerabilities in the carbon-climate-human system, Tellus B, 63, 145-164, doi:10.1111/j.1600-0889.2010.00521.x, 2011.

Rayner, P. J., Raupach, M. R., Paget, M., Peylin, P., and Koffi, E.: A new global gridded data set of $\mathrm{CO}_{2}$ emissions from fossil fuel combustion: Methodology and evaluation, J. Geophys. Res., 115, D19306, doi:10.1029/2009JD013439, 2010.

Ribeiro, S. K. and Kobayashi, S.: Transport and its infrastructure, in Climate Change 2007: Mitigation of Climate Change, edited by: Metz, B., Davidson, O. R., Bosch, P. R., Dave, R., and Meyer, L.A., 325-385, Cambridge University Press, Cambridge, U. K., 2007.

Sadorsky, P.: Trade and energy consumption in the Middle East, Energ. Econ., 33, 739-749, doi:10.1016/j.eneco.2010.12.012, 2011.

Saxon, E. C., Parris, T., and Elvidge, C. D.: Satellite surveillance of national $\mathrm{CO}_{2}$ emissions from fossil fuels, Harvard Institute for International Development (Harvard University), Development Discussion Paper No. 608, available at: http://www.cid.harvard. edu/hiid/608.pdf, 1997.

Suntharalingam, P., Randerson, J.T., Krakauer, N., Logan, J. A., and Jacob, D. J.: Influence of reduced carbon emissions and 
oxidation on the distribution of atmospheric $\mathrm{CO}_{2}$ : Implications for inversion analyses, Global Biogeochem. Cy., 19, GB4003, doi:10.1029/2005GB002466, 2005.

Turnbull, J. C., Miller, J. B., Lehman, S. J., Tans, P. P., Sparks, R. J., and Southon $\mathrm{J} .:$ Comparison of ${ }^{14} \mathrm{CO}_{2}, \mathrm{CO}$, and $\mathrm{SF}_{6}$ as tracers for recently added fossil fuel $\mathrm{CO}_{2}$ in the atmosphere and implications for biological $\mathrm{CO}_{2}$ exchange, Geophys. Res. Lett., 33, L01817, doi:10.1029/2005GL024213, 2006.

Turnbull, J. C., Karion, A., Fischer, M. L., Faloona, I., Guilderson, T., Lehman, S. J., Miller, B. R., Miller, J. B., Montzka, S., Sherwood, T., Saripalli, S., Sweeney, C., and Tans, P. P.: Assessment of fossil fuel carbon dioxide and other anthropogenic trace gas emissions from airborne measurements over Sacramento, California in spring 2009, Atmos. Chem. Phys., 11, 705-721, doi:10.5194/acp-11-705-2011, 2011.

United Nations Framework Convention on Climate Change (UNFCC): United Nations, New York, 25 pp., 1992.

UNFCCC: United Nations Framework Convention on Climate Change (UNFCCC) Greenhouse Gas Inventory Data, Technical Report, Bonn, Germany, available at: http://unfccc.int/ghg_data/ items/3800.php, 2004.
United States Environmental Protection Agency (USEPA): US emissions inventory 2006-Inventory of US greenhouse gas emissions and sinks: 1990-2004, Washington, D. C., 2006.

Van Aardenne, J. A., Dentener, F. J., Olivier, J. G. J., Klein Goldewijk, C. G. M., and Lelieveld, J.: A $1^{\circ} \times 1^{\circ}$ resolution data set of historical anthropogenic trace gas emissions for the period 1890-1990, Global Biogeochem. Cy., 15, 909-928, doi:10.1029/2000GB001265, 2001.

Van Aardenne, J. A., Dentener, F. J., Olivier, J. G. J., Peters, J. A. H. W., and Ganzeveld, L. N.: The EDGAR 3.2 Fast track 2000 dataset (32FT2000), Technical Report, Joint Research Centre (JRC), Ispra, Italy, available at: http://www.mnp.nl/edgar/model/ v32ft2000edgar, 2005.

Vogel, F. R., Hammer, S., Steinhof, A., Kromer, B., and Levin, I.: Implication of weekly and diurnal ${ }^{14} \mathrm{C}$ calibration on hourly estimates of CO-based fossil fuel $\mathrm{CO}_{2}$ at a moderately polluted site in southwestern Germany, Tellus B, 62, 512-520, doi:10.1111/j.1600-0889.2010.00477.x, 2010.

Zickfeld, K., Eby, M., Matthews, H. D., and Weaver, A. J.: Setting cumulative emissions targets to reduce the risk of dangerous climate change, P. Natl. Acad. Sci. USA, 106, 16129-16134, doi:10.1073/pnas.0805800106, 2009. 